\title{
The benefits of a granular interface over pyritic subgrade
}

1 Mourice A. Czerewko BSc (Hons), DipHS, MSc, PhD, CGeol, EurGeol, FGS

Associate Engineering Geologist, AECOM, Chesterfield, UK
2 Stephen A. Cross BEng, Eng Tech, TMICE

Principal Geotechnical Engineer, AECOM, Chesterfield, UK
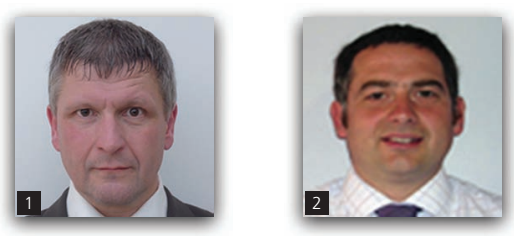

Construction and improvement of the arterial highway infrastructure in the UK often encounters areas of pyritic ground. Pyrite bearing subgrades, particularly mudrocks, have a strong likelihood to be problematic due to oxidation producing both volumetric and mineralogical changes in the host deposit. Consideration of the possible adverse implications to the highway tends to be overlooked without exploring the possibilities and consequences of subgrade and earthwork material degradation. Protection to road pavements may be best achieved by the inclusion of a granular construction interface separating the pavement construction from the potentially deleterious underlying pyritic subgrade. Traditional road construction relied on an empirical approach for foundation design with inclusion of granular capping over low-strength subgrades as protection. Revision to the guidance in the last decade has introduced a performance-based approach which leaves the decision to include a granular capping with the designer. Therefore, if pyritic subgrades were present, the absence of a granular separator layer may expose the road pavement and associated structures to the consequences of ground movements and aggressive ground conditions. This paper presents three road construction cases involving pyritic mudstone subgrades to demonstrate the benefits of inert granular construction interfaces in achieving road pavement integrity.

\section{Notation}

C Hazen's coefficient for water (in terms of $h_{\mathrm{c}}$ )

$c^{\prime} \quad$ cohesion in effective stress terms

$c_{\mathrm{u}} \quad$ undrained cohesion

$c_{\mathrm{v}} \quad$ coefficient of consolidation, vertical direction

$D_{10} \quad$ particle size at $10 \%$ passing, effective size

e void ratio

$h_{\mathrm{c}} \quad$ capillary rise

$I_{\mathrm{d} 2} \quad$ two-cycle slake durability index (determined using slake durability test)

$I_{\mathrm{j}^{\prime}} \quad$ static durability index (determined using jar slake test)

$I_{\mathrm{p}} \quad$ plastic index (or PI)

$m_{\mathrm{v}} \quad$ coefficient of volume compression

$w \quad$ moisture content or water content

$w_{\mathrm{L}} \quad$ liquid limit (or LL)

$w_{\mathrm{P}} \quad$ plastic limit (or PL)

$\phi^{\prime} \quad$ friction angle in effective stress terms

\section{Introduction}

Changes in the road design and construction process over the last decade have been encapsulated in the Highways Agency guidance, IAN 73/06 Rev 1 (HA, 2009a). This has typically seen the phasing out of unbound capping layers within pavement construction, other than limited use for lower foundation classes and as an improvement option where the subgrade does not have appropriate stiffness for the required foundation conditions.

The previous standard, HD 25/94 (HA, 1994) required a granular capping layer as part of the road construction in situations where the subgrade was deemed insufficient to satisfy the requirements for appropriate long-term bearing, such as for clay soils. Under these circumstances, a capping layer was included in the construction and the required thickness of the capping layer was commensurate with the design CBR (California bearing ratio) value derived from material correlation tables.

This granular layer would be engineered at the sub-formation level between the prepared subgrade surface and the overlying sub-base and pavement layers. Options allowed for inclusion of the cheaper capping material as an alternative to increasing the thickness of more expensive sub-base aggregate to provide the required strengthening of the subgrade. Such procedures over the years have served sufficiently well in the authors' opinion to mitigate against potential deleterious degradation of the highway, both in terms of long-term softening of the foundation layers, often attributed to groundwater effects and inadequate drainage, 
and also as mitigation against potentially deleterious sulfate-rich groundwater derived from the weathering of pyrite.

When the resilience of the subgrade has been determined to be unsuitable, the current design process leaves the decision with the design team to determine the requirement for ground improvements, including replacement, provision of a capping layer or soil improvement. Due to the rising costs of natural aggregates and the tighter profit margins in construction, the capping option is often looked on as a seemingly unnecessary and costly component of the road layer, with soil improvement the preferred solution unless chemically impractical.

An aspect which tends to be overlooked and not adequately considered is the implication from the potentially deleterious pyritic component of many subgrades, including ancient over-consolidated clays and mudstones. Previously, the granular capping layer will have inadvertently mediated for the effects associated with pyritic oxidation including subgrade degradation, heave and aggressive ground conditions. In the absence of a granular interface, the hydraulically bound and unbound road base layers in contact with pyritic subgrade are susceptible to damage from heave and aggressive chemical conditions associated with pyrite oxidation.

The function of a road foundation is to provide adequate protection to the subgrade from environmental effects, provide a pavement construction platform and provide adequate support to the overlying pavement through the service life of the road (Chaddock and Roberts, 2006). Therefore, the road foundation is engineered to control subgrade deformation from traffic-induced stresses during construction and through the service life of the road. The assessment of subgrade for road design relies on determination of immediate bearing characteristics and ground stiffness based on resilience and bearing modulus. These parameters are determined by in situ testing of the prepared formation material, which is generally carried out under favourable weather conditions. These conditions do not reflect the long-term situation, particularly where subgrade material is susceptible to rapid chemical weathering. Long-term stiffness is modelled using the initial tested stiffness and factored for likely stress effects that may develop during the life of the road, brought about from the anticipated use for which a suitable pavement foundation design is derived.

The process does not consider the effects of subgrade degradation brought about by chemical changes. In particular, this poses serious implications when pyrite is a component of the subgrade. The latest standard IAN 73/06 (HA, 2009a) guides the design team towards a soil improvement layer, where the soil has insufficient stiffness. Only when soil improvement is assessed to be chemically impractical, is granular capping considered. The deleterious consequences that may develop as a result of pyrite oxidation are not considered. The long-term benefits offered by granular capping for mitigating for the consequences associated with pyrite oxidation tend not to be recognised. Pyrite-bearing materials have a tendency to weather and degrade in a more rapid and catastrophic manner than their non-pyritous analogues. In these circumstances, the subbase and lower pavement layers formed onto pyritic subgrade of sufficient strength and stiffness offer no protection to the deleterious effects of degradation.

Pyrite is a minor but very significant constituent of many types of mudrocks and argillaceous limestones, especially darkcoloured, organic-rich examples. Because pyrite is chemically unstable in the presence of oxygen and water, exposure to the weathering environment results in the formation of sulfate-rich acidic pore waters. Although chemical oxidation is very slow, bacterial action can result in a massive increase in the reaction rate (Sasaki et al., 1998), so that the changes occur within engineering timescales and often during the highway construction phase (Czerewko et al., 2011). This is likely to include a number of significantly deleterious consequences to highway schemes, including rapid degradation of the subgrade and decline of geotechnical properties (Cripps and Edwards, 1997); chemical attack of concrete and other construction materials (Thaumasite Expert Group, 1999); precipitation of reaction products, which leads to heave and uplift pressures that affect shallow foundations (Hawkins and Pinches, 1987), embankment (Pye and Miller, 1990) and highway construction, slopes, fills and stabilised soils (Snedker and Temporal, 1990). Hawkins (2014) reviews a number of cases of foundation damage to structures and highways due to heave associated with oxidation of pyrite present in the underlying subgrade or structural fill materials. In many of the cases, the implications were largely unsuspected during development and occurred soon after construction. But the main challenge for ground assessment and design is in the difficulty in predicting whether problems will occur and to what extent.

\section{General elements of road construction}

There are two main types of road structure, flexible and rigid, with a third composite option preferred in recent decades. Rigid roads consist of a thick concrete top surface and require more specialised equipment for construction but are preferred over ground liable to settle or with potential for void formation. Otherwise, preference is for flexible and composite roads. Composite road construction includes a flexible layer over a rigid surface such as a hydraulically bound material (HBM), or where a concrete layer exists below a bitumen top surface.

When a road is built, the surface is dug out down to the designed depth of the intended road. Preparation is carried out on the ground now exposed below (such as compaction). The road itself will then be built up above, usually consisting of four layers (see Figure 1).

- The sub-grade is the ground below the road layers which is exposed once the ground has been dug out ready to build the road. The top level of this is termed the formation.

- The traditional capping was a layer added above the sub-grade to protect it in new construction. In this case, 


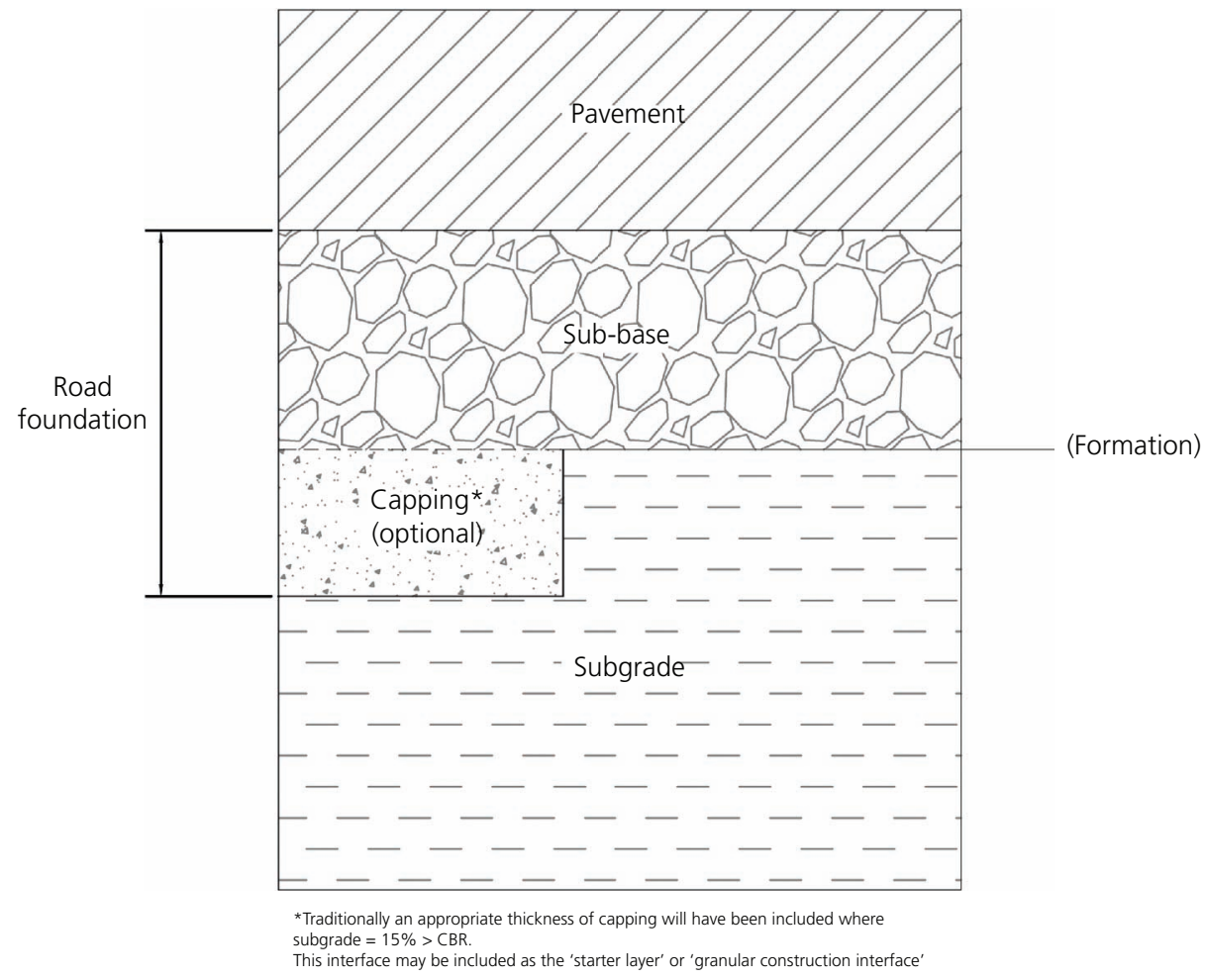

Figure 1. General structure of British Roads

the top layer of the capping would constitute the formation.

- The sub-base is a layer of unbound material laid down as soon as possible after final stripping to formation level, to prevent damage from weathering and construction trafficking. The most commonly used material for use in sub-bases is termed Type 1. This is an unbound material made from inert aggregates including crushed rock, crushed slag, crushed concrete and recycled aggregates. It contains particles of various sizes, the percentage of each size being within a defined range. Up to $10 \%$ may be natural sand. The predefined and calculated range of material sizes contained means that once properly compacted, it will resist further movement within its structure. The specified product is costly and therefore other materials have become popular for the construction of sub-bases, including bituminous-bound materials and concrete and cement-bound materials which allow the use of excavated and recycled material and require a thinner layer without the need for a capping layer.

- The pavement layer comprising the base, binder course and surface course.

The use of HBMs has become more popular in road construction over the last few decades. HBMs promote the use of recycled and secondary aggregates in a hydraulically bound form allowing significant cost savings over traditional flexible pavement construction. HBMs are mixtures that set and harden by hydraulic reaction and have a water content suited for compaction by rolling. These include cement-bound mixtures (CBM) using Portland cement which are fast setting, as well as slow-setting mixtures that use components such as pulverised fuel ash (pfa), granulated blast-furnace slag or other chemical compounds as binders.

All types of road construction, including flexible, rigid to semirigid/composite, irrespective of their construction benefits, are susceptible to the deleterious effects of pyritic subgrades from which aggressive conditions and ground heave are produced by weathering. These are further described in this paper.

\section{Pyrite distribution in geological deposits}

Aggressive ground conditions may be attributed to a wide range of environmental factors, although a high proportion affecting the engineering environment can be attributed to sulfur minerals that give rise to high concentrations of sulfate ions and aggressive acidic conditions (Cripps and Edwards, 1997). Sulfur occurs in geological deposits principally as sulfate $\left(\mathrm{SO}_{4}{ }^{2-}\right)$ and sulfide $\left(\mathrm{S}^{-}\right.$ or $\mathrm{S}^{2-}$ ), but it also occurs as elemental sulfur and organic sulfur. Elemental sulfur and sulfides are the stable forms of sulfur under anaerobic conditions, whereas sulfates are the stable form of sulfur under aerobic conditions. Organic sulfur tends to be stable under both situations.

Of the sulfide minerals, the iron forms are the most common and most widely occurring; they easily oxidise and are of greatest concern to the built environment. Sulfide minerals form 
under anaerobic conditions from sulfates already present in the water or sediment. As the sulfate ion cannot be reduced to a sulfide at surface temperatures and pressures, the process requires microbial mediation. Under these anoxic aquatic sedimentary environments, the reaction between iron (released through dissolution of detrital oxides and silicates) and sulfide (produced by the bacterial reduction of sulfates) produces the iron disulfide mineral phase through its unstable iron monosulfide precursor. The products of this process tend to develop as agglomerations of poorly formed microcrystals, too small to be observed by eye.

Diagenetic changes brought about through burial subject sediment deposits to increasing temperatures and pressures transforming them to rocks through partial to complete melt. The process converts the small poorly formed microcrystals into larger cubic or multifaceted crystals or solid masses through recrystallisation. Consequently, sulfide minerals are found in most geological deposits, including igneous and metamorphic rocks, ore deposits and sedimentary deposits formed under sulfur-rich anoxic conditions.

The most abundant of the sulfide minerals is the iron disulfide mineral pyrite $\left(\mathrm{FeS}_{2}\right)$, which has a densely packed cubic crystal structure producing its hard brittle nature. Marcasite, sometimes referred to as white iron pyrite, is a dimorph of pyrite and has a less dense orthorhombic crystal structure producing its unstable brittle nature. Marcasite is less widely distributed than pyrite; it is typically found in low-temperature sedimentary deposits. Historically, the term 'iron pyrite' has been used in reference to both (Bowles et al., 2011).

Pyrite is remarkably widespread and is well known as an accessory mineral in many of the major rock and sediment types which make up the crust of the Earth. Igneous and metamorphic deposits and their associated ores frequently contain pyrite, which may achieve substantial concentrations in some examples of ultrabasic and basic intrusive rocks. In acidic to intermediate igneous rocks and associated ore deposits, as well as areas of contact metamorphism associated with granitic intrusions, the deposits contain well-formed fine- to coarse-size grains typically as cubes or multifaceted crystals distributed throughout the host rock. Pyrite is often a major phase in hydrothermal vein deposits, where it can occur as coarse-grained aggregates. Often, crystals may have well-formed faces or occur as banded or massive varieties.

The disseminated form of pyrite is also a major component of volcano-sedimentary and sediment-hosted ore deposits, including black mudstones, dolomite or associated sandstone units, which may have undergone mild folding and metamorphism. Within these disseminated deposits, pyrite occurs in its characteristic fine-grained framboidal form. Although the non-sedimentary deposits that are described tend to be less frequently encountered during civil engineering works in the UK, they constitute a major source of construction aggregates and therefore may be potentially deleterious.

The forms of pyrite found in nature depend on the conditions in which they form. Well-crystallised forms of pyrite occur as large masses, veins, or as large discrete cubic or multifaceted octahedral or pyritohedral crystals of a few millimetres to a few centimetres in dimension. Typically, these are found in rocks that have been subject to moderate to high temperatures and pressures. These well-crystallised forms of pyrite have a densely packed structure and relatively small specific surface area.

Whereas the poorly crystallised 'framboidal' form of pyrite occurs as microscopic raspberry-like aggregates of tiny particles of pyrite which are typically found in deposits of sedimentary and low temperature hydrothermal origin, pyrite framboids and coalesced polyframboids consist of individual, generally euhedral microcrystals typically $<1-5 \mu \mathrm{m}$ in size, forming ordered spherical aggregates of up to $25-50 \mu \mathrm{m}$ in size (Figure 2), which are clearly beyond the limit of optical detection. The clusters of microcrystals that form framboids tend to be held together by weak bonding and expose a large specific surface area making them susceptible to weathering. Therefore, the microscopic framboidal form of pyrite is much more reactive than larger observable well-formed pyrite crystals (Figure 3) and dense masses found in medium- to hightemperature deposits.

In low-temperature sedimentary environments, typical of shallow water sea floor or inland aquatic environments, pyrite forms in muds under reducing conditions and occurs disseminated in clays, mudstones and carbonate rocks derived from these environments. Such deposits are typical of the Carboniferous Coal Measures and Jurassic to Eocene age marine deposits that occur at sub-crop over much of the urban areas of the UK (Figure 4).

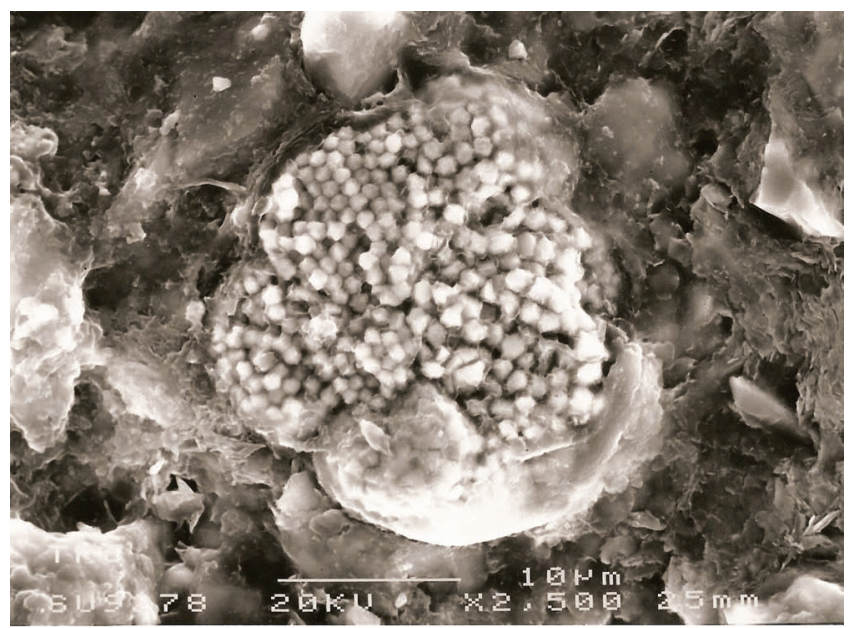

Figure 2. Pyrite polyframboid in Lower Lias Clay 
The benefits of a granular interface over

pyritic subgrade

Czerewko and Cross

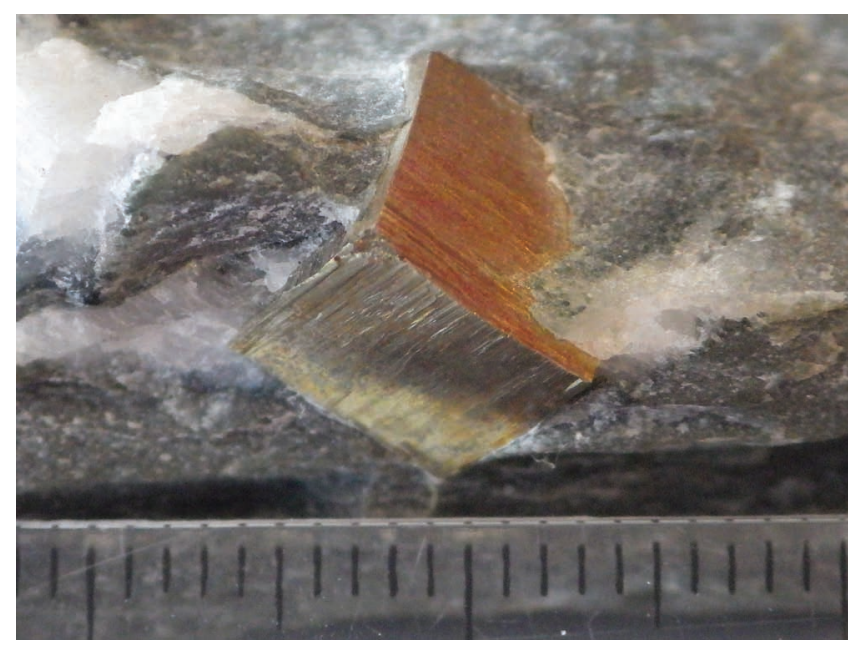

Figure 3. Well-formed pyrite cube in Cambrian slate
Most consequential to civil engineering is the framboidal form of pyrite, widely found as an accessory mineral in these sedimentary sequences, particularly grey-coloured mudstone, where it is often undetected (Figure 5), and coal deposits. Here, when present, the pyrite is generally of a fine-grained disseminated form and, occasionally, also as visible nodules or clusters of well-formed cubic crystals in more indurated sedimentary deposits (Figure 6). Sedimentary rocks other than those formed from fine-grained deposits may also contain pyrite. For example, pyrite occurs in chalk deposits and is often present in ancient limestone sequences. It also occurs in sandstones associated with finer-grained marine sediments such as the Jurassic Group sediments.

\section{Pyrite weathering}

The complications posed by pyrite generally centre on the byproducts of the oxidation process leading to rapid degradation of in situ deposits. Both oxygen and water are necessary for pyrite oxidation, making it unstable under atmospheric conditions. The

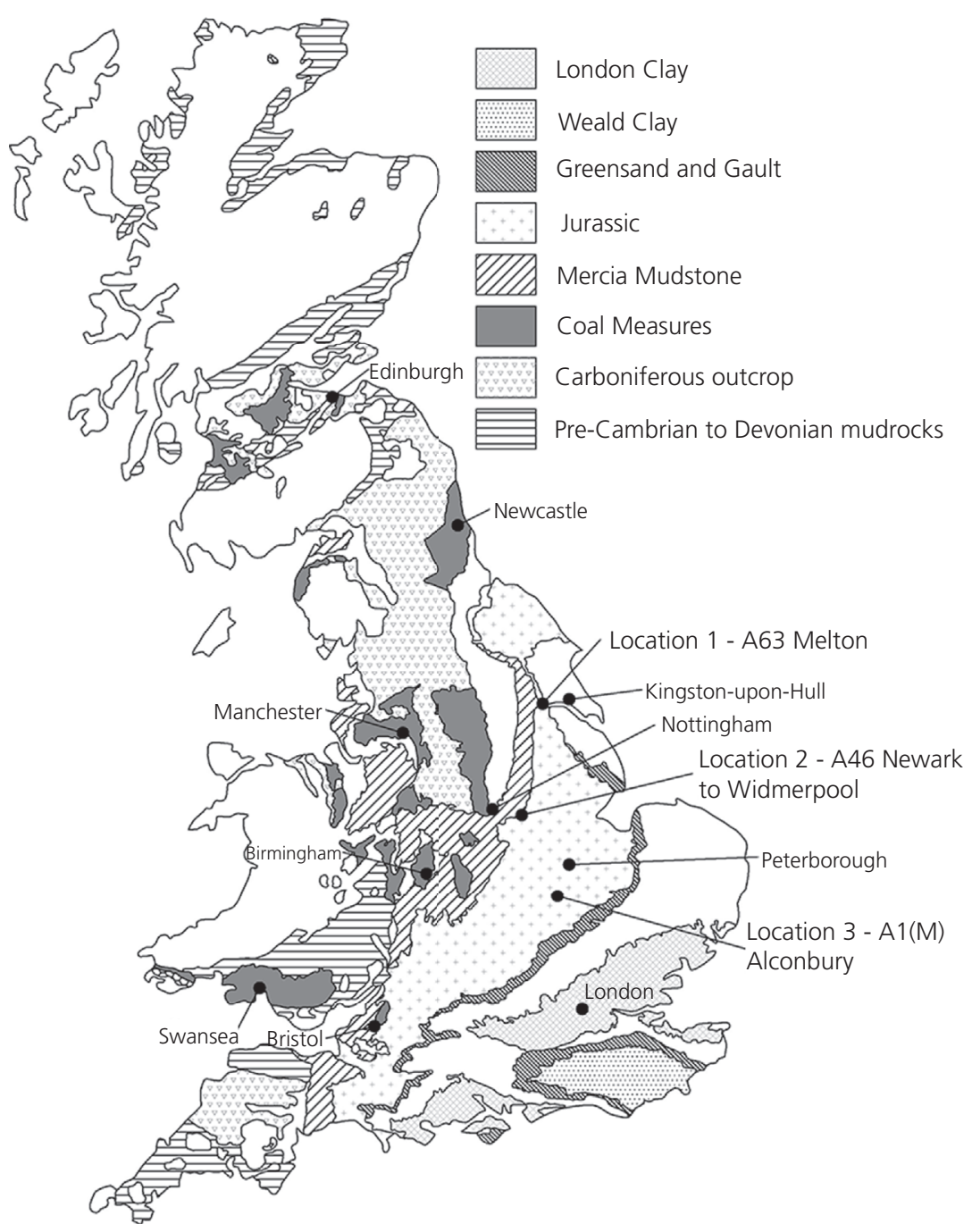

Figure 4. Distribution of principal pyrite deposits in the UK 
The benefits of a granular interface over

pyritic subgrade

Czerewko and Cross

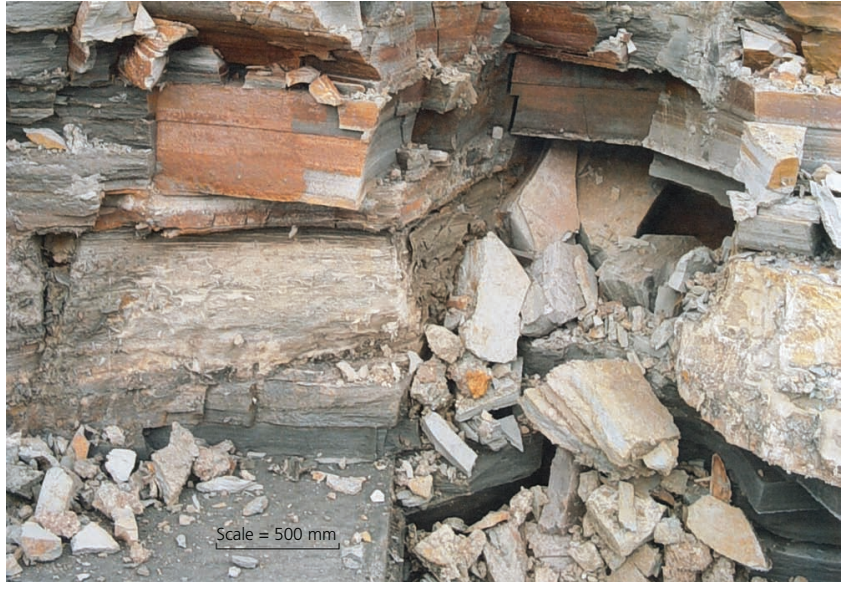

Figure 5. Lower Lias pyritic mudstone

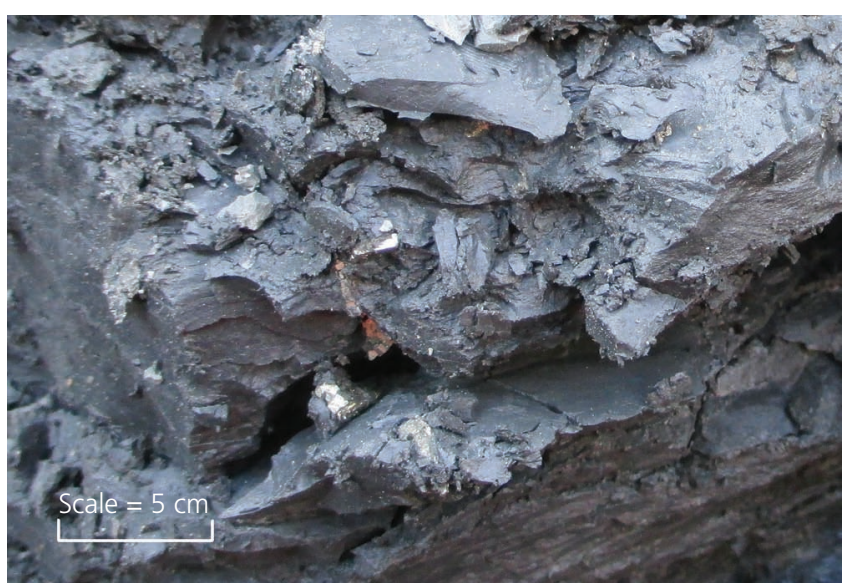

Figure 6. Cluster of pyrite cubes in Westbury Mudstone

oxidation of pyrite involves both chemical and microbial processes, which enhance the rate of degradation by a few orders of magnitude. The reactivity of pyrite depends on the form, condition and grain size of the individual crystals or microcrystals and on the permeability and chemistry of the host rock and groundwaters.

Typically, the oxidation reaction proceeds more rapidly when pyrite is present as small discrete crystals or framboidal aggregates, partly due to the large collective surface areas which are up to ten times greater and typically of a less dense structure than found in the well-crystallised analogues (Pugh et al., 1981). Since the oxidation of framboidal pyrite is inevitable and often rapid following exposure to atmospheric conditions, it has been defined as the 'reactive form of pyrite'. Reaction commences on exposure to the surface weathering environments provoking a high production of acidic conditions and sulfate ions and yellow brown to orange brown amorphous iron hydroxide/oxide precipitate. The oxidation process can be greatly accelerated in scale and rate by the activities of certain bacteria of natural ubiquitous occurrence, such as the genus Acidithiobacillus (Pye and Miller, 1990). Although complex and involving a number of possible intermediate stages, the reaction can be demonstrated by its simplified form shown in Equation 1

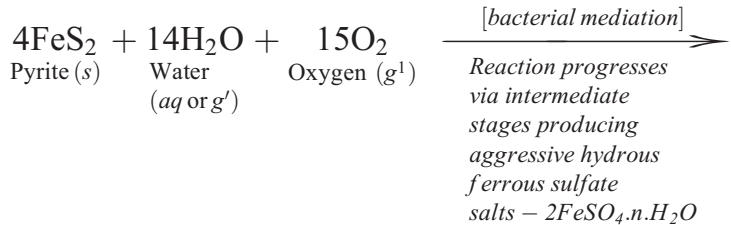$$
4 \mathrm{Fe}(\mathrm{OH})_{3}+8 \mathrm{H}_{2} \mathrm{SO}_{4}
$$

1. Limonite/ochre $(s) \quad$ Sulfuric acid $(a q)$

[ $s$ = solid; $a q=$ aqueous or liquid; $g^{\prime}=$ atmospheric gas/humidity; $g^{1}=$ gas and may occur dissolved in oxygenated water]

The oxidation reaction is strongly affected by the nature of the pyrite and various environmental factors present during exposure. Therefore, it is a complicated mechanism and is not completely understood and difficult to predict with complete certainty other than that it requires oxygen and water to proceed. More detailed reviews of the reaction stages are discussed further by Hawkins and Pinches (1987), Lowson (1982) and Reid et al. (2005).

In contrast, the buffering of the products is a straightforward acid-base reaction, which may be predicted from knowledge of the host mineralogy. As a result of the chemical degradation, the sulfuric acid produced will attack other components present in the ground, creating new minerals. In clay-rich carbonate poor materials, the yellow-brown to red-brown jarosite-alunite sulfate mineral series will form. Whereas in the presence of carbonate minerals, particularly calcite, the reaction between calcite and the sulfuric acid leads to crystallisation of gypsum as 'selenite' as demonstrated in Equation 2

$$
\begin{aligned}
& \underset{\text { Sulfuric acid }(a q)}{\mathrm{H}_{2} \mathrm{SO}_{4}}+\underset{\text { Calcite }(s)}{\mathrm{CaCO}_{3}}+\underset{\text { Water }(a q)}{\mathrm{H}_{2} \mathrm{O}} \\
& \text { 2. } \underset{\text { Selenite-Gypsum }(s)}{\mathrm{CaSO}_{4} \cdot 2 \mathrm{H}_{2} \mathrm{O}}+\underset{\text { Carbon dioxide }(g)}{\mathrm{CO}_{2}}
\end{aligned}
$$

$[s=$ solid; $a q=$ aqueous or liquid; $g=$ gas $]$

Calcite is a characteristic component of marine mud deposits forming discrete strata, cements, concretions or fossil debris. It is present as a characteristic component in most of the problematic lithologies encountered during earthworks in the UK and therefore constitutes a principal reaction process. Typically, partially weathered mudrock deposits may contain selenite crystals and saccharoidal selenite grains (Figure 7) which are frequently observed adjacent to degraded fossil debris (Figure 8) 
The benefits of a granular interface over

pyritic subgrade

Czerewko and Cross

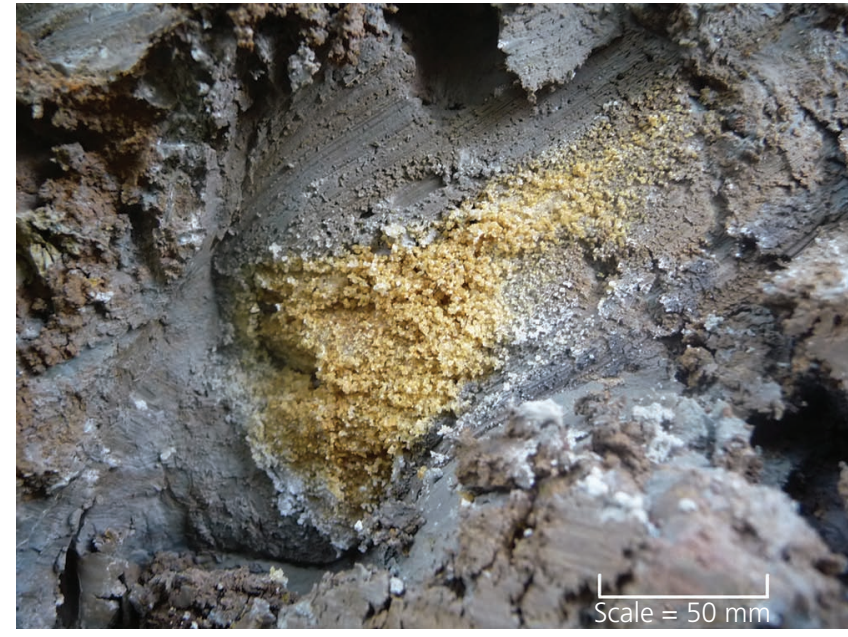

Figure 7. 'Sand-like' pocket of iron-stained saccharoidal selenite

or in pockets resembling sand, with yellow to orange-brown limonite replacement and at bedding and discontinuity interfaces in more competent material (Figures 9 and 10).

\section{Implications of pyrite oxidation for highway construction}

Earthworks can give rise to pyrite weathering through the exposure of pyrite-bearing horizons to atmospheric conditions. In some cases, lowering of the water table exposing pyritic lithologies has been responsible for oxidation. Following ground disturbance and exposure to the weathering environment, pyrite is liable to degrade, producing an acidic environment by the development of sulfuric acid. The sulfuric acid in itself produces an environment aggressive to construction material, being corrosive to buried steel and concrete, and can raise the sulfate levels of the ground surrounding cementitious material and

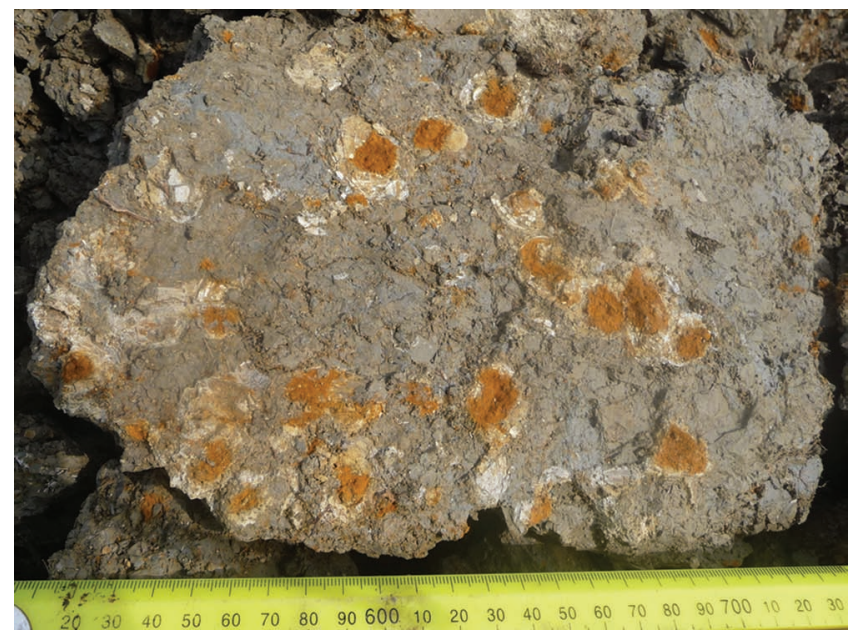

Figure 8. Degraded fossil debris with orange hydrated iron oxide replacing former pyrite infill

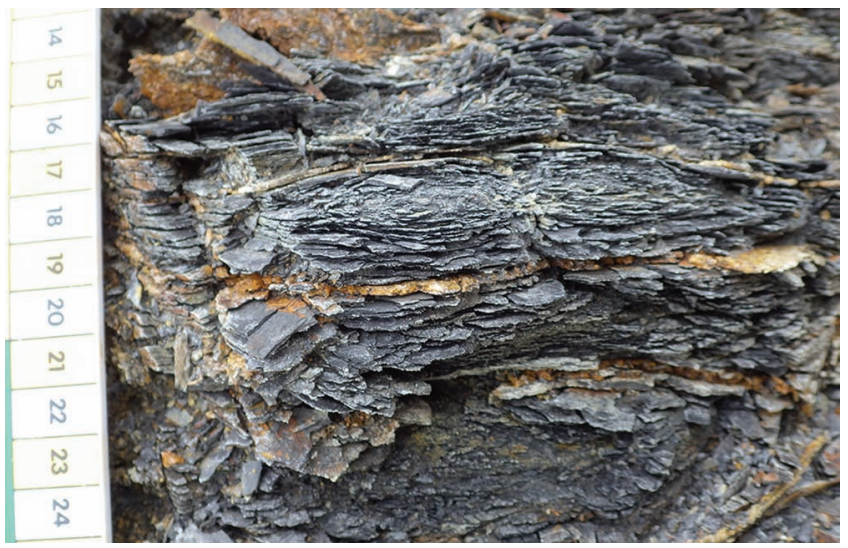

Figure 9. Orange-stained selenite precipitation in discontinuities, Edale Shale, Mam Tor landslip, Derbyshire

buried concrete to harmful levels (Czerewko et al., 2002; Snedker and Temporal, 1990; West, 1996).

But, it will also react with other minerals present in the ground such as carbonates, particularly calcium carbonate (calcite) $\left(\mathrm{CaCO}_{3}\right)$, to form gypsum (Cripps et al., 1993; Hawkins and Pinches, 1987). Calcite is a common constituent in many geological deposits, particularly marine clays, mudrocks, calcareous deposits and sandstones, where it occurs as fine particles, nodules, discrete horizons and shell debris.

The replacement of pyrite and calcite by gypsum is significantly expansive. Gypsum crystals (termed selenite) cause heave due to the larger volume occupied by the products than formerly occupied by the starting minerals. This is partly due to the density difference resulting from the chemical reaction (Bell, 1992), with the simple replacement of calcite by gypsum producing an increase in volume of $103 \%$ (Taylor and Cripps,

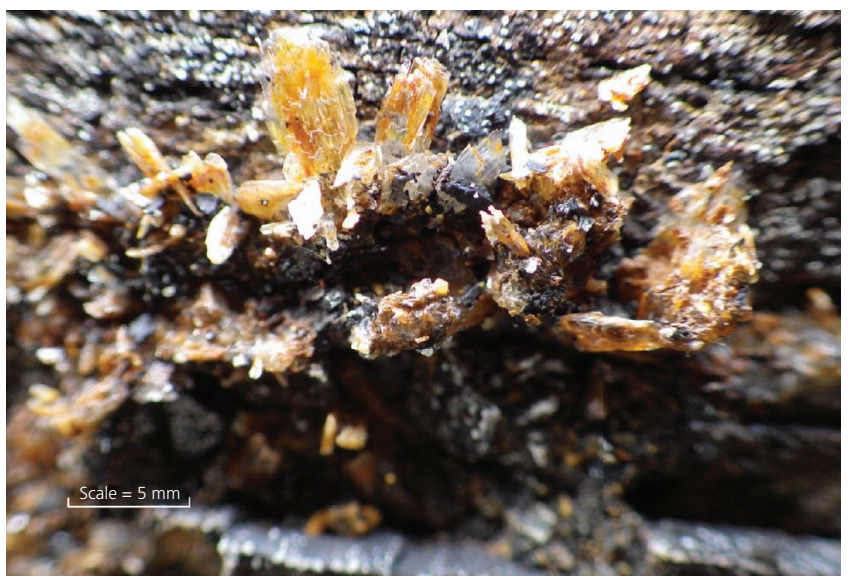

Figure 10. Close up of Figure 8 showing selenite crystal growth separating the discontinuity faces 
Geotechnical Research

Volume 2 Issue 3
The benefits of a granular interface over

pyritic subgrade

Czerewko and Cross
1984). The precipitation of gypsum can exert pressures of up to $100-500 \mathrm{kPa}$ in confined conditions leading to differential ground heave (Taylor and Cripps, 1984). This reaction may occur at some distance from the site of hydration and oxidation resulting in a net transport of sulfur from the original location. Too high a content of calcium carbonate may neutralise the acidic environment produced, therefore rendering the environment unsuitable to microbes and slowing down the rate of pyrite oxidation (Hawkins and Pinches, 1997). Smaller quantities of calcite are preferable and a range of $0.5-8 \%$ calcium carbonate seems to be optimum, although higher concentrations of calcium carbonate may be tolerated in situations where high through-flow of groundwater exist, such as in stockpiles or disturbed ground, where an acidic environment is maintained and the buffering reaction contact time reduced by high water flow.

The process involved in pyrite degradation, removal of calcite and formation of gypsum adversely affects the ground materials with disruption of the fabric. This in part is caused by the dissolution and removal of cement constituents such as calcite and pyrite, which increases the porosity and permeability of the host material, enabling greater movement of oxygenated water, which further increases the rate of weathering. Consequently, the changes brought about exacerbate otherwise favourable geotechnical properties destructuring the ground material and compromising its integrity leading to reduction in strength and increase in plasticity and compressibility. Pyrite is also unstable under alkali conditions with $\mathrm{pH}>10$, where oxidation occurs by purely chemical means without microbial influence. Ground disturbance and alkali conditions are both inherent in soil stabilisation, the conditions become conducive to pyrite oxidation causing sulfate attack with the formation of expansive materials such as ettringite and thaumasite (Higgins et al., 2002).

When the presence of framboidal pyrite is suspected, the amount of sulfide-sulfur (referred to as oxidisable sulfide - 'OS' in BRE, 2005 and Reid et al., 2005) is a good indicator of the potential for oxidation to occur within the subgrade which can produce deleterious consequences. Heave caused by the pyrite oxidation process has been recorded from materials containing as little as $0 \cdot 1 \% \mathrm{~S}$ as oxidisable sulfide (Belgeri and Siegel, 1998).

The relative proportion of sulfate-sulfur is indicative of the degree of weathering that has already occurred. Sulfate crystals such as selenite will develop in capillary zones and tend to localise and grow along discontinuities within the ground mass due to reduced stress in these regions. They may also concentrate within voids and construction planes or at groundwater seepage zones at ground surface, such as in stockpiles. Since gypsum precipitates by nucleation, expansion tends to be caused by growth of discrete crystals and not by systematic filling of void space. Therefore, the effects of heave from discrete points of nucleating crystallisation are proportionally much larger than if discontinuities were completely filled on a systematic manner.
In well-indurated cementation mudrocks, the growth of sulfate minerals as bladed selenite crystals in a stratified manner along well-developed horizontal bedding planes and sub-horizontal fissility (Figure 9) is a dominant factor in vertical heave (Hawkins and Pinches, 1997). Whereas, in less well-indurated soil, like compaction mudrocks and clay deposits, pyrite tends to occur as a fine disseminated component, which on oxidation will react with any calcite present resulting in the formation of randomly distributed gypsum crystals, producing a more uniform heave in vertical and horizontal directions (Figures 11 and 12).

The selenite form of gypsum tends to have a low solubility, and once it crystallises, it is not easily redissolved in groundwater unless conditions are acidic (Hawkins and Pinches, 1997).

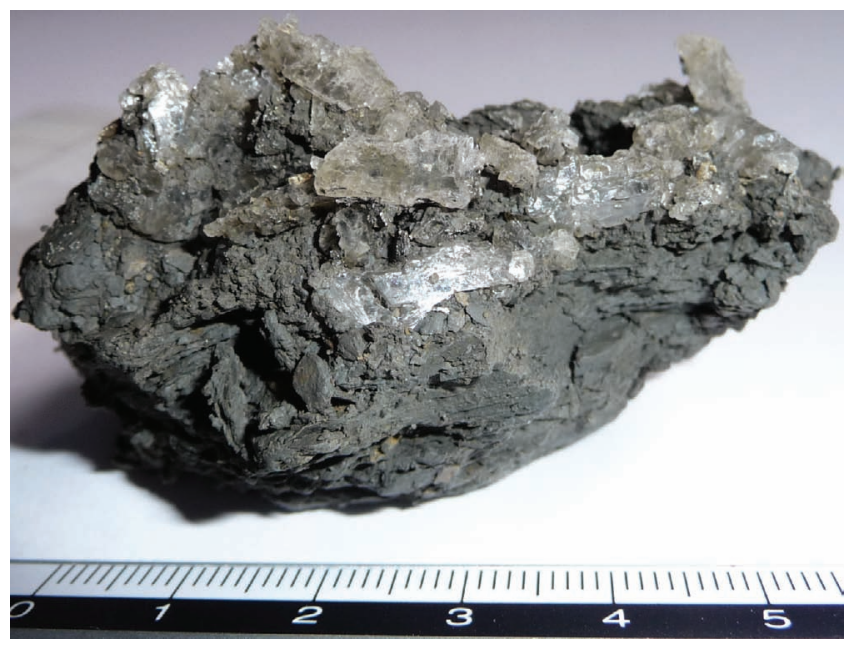

Figure 11. Selenite crystals disrupting mudrock fabric

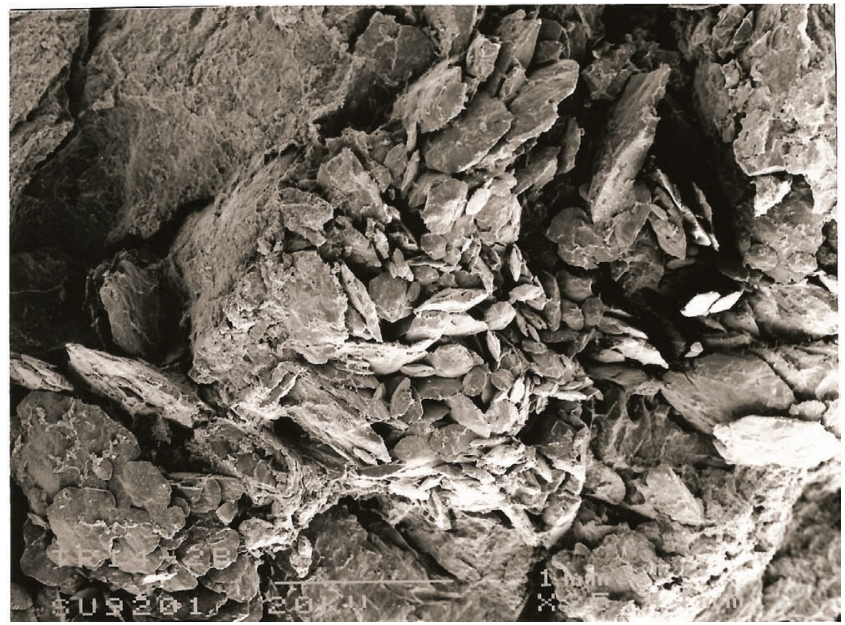

Figure 12. Electron microscope image of selenite crystals causing fabric disruption and fissuring 
This may present a significant consequence for ground heave in highway development as, while gypsiferous waters are mobile during the earthworks phase, they will start to precipitate at construction boundaries as discrete crystals with potential for further nucleation on completion of the work, producing volume change and ground heave in the absence of appropriate remedial measures.

Although these reactions occur rapidly following exposure to oxygen and water, the effects may take longer to cause heave, depending on many factors, including pyrite form, solute migration through the medium, environmental conditions and confining pressure. Air and water are required in appropriate quantities for the reactions and to transport reaction products.

In typical pavement construction, the heave process may be driven kinetically by higher temperatures at road surface causing capillary rise of sulfate-rich pore fluids within the pavement layers that are produced by pyrite oxidation at the subgrade interface.

The amount of ground movement can be quite catastrophic to lightly loaded structures, as demonstrated by a case of pyriterelated ground heave in which 1000 wooden houses were damaged at a residential development in Japan, where ground heave of up to $480 \mathrm{~mm}$ was recorded and the estimated cost of repairs to the damaged properties ran to 10 billion yen of expenses (Yamanaka et al., 2002). The mudstone bedrock at the site contained $5 \%$ pyrite. During a period of dry weather, the previously high water content of the pyrite-bearing mudrock was lowered due to exposure following construction resulting in desiccation of the ground. As a consequence, the mudstone became permeable to air and sulfur-oxidising bacteria and the pyrite rapidly oxidised. The sulfuric acid produced reacted with the calcite present in the mudstone leading to the formation of gypsum causing vertical heave with significant structural damage. The situation described is similar to that encountered in many cases of highway construction in the UK and demonstrates the potential implications that may develop.

In the UK, pyrite is commonly found as a minor component of organic rich argillaceous marine deposits of Recent to Carboniferous age and older (BRE, 2005; Reid et al., 2005). It may be present as visible nodules or crystal clusters in the more indurated deposits, but more typically, it occurs as disseminated microscopic framboids which are difficult to detect in the unweathered, dark-coloured strata in which they are found. It is assumed that towards the end of the Triassic Period, the Rhaetic marine transgression spread shallow waters of the marginal Tethys Ocean over the desert landscape of Britain which laid down alternating sequences of clays with subordinate limestones and heralded the start of the Jurassic Period.

The Jurassic marine mudrock sequences commonly contain significant pyrite and occur extensively in central, eastern and southern England (Figure 4). They extend from the Yorkshire and Cleveland coasts in the north, through the East Midlands, the Cotswolds and to the Dorset coast in the south. They are bordered to the south and west by a thin fringe of very distinct pyritebearing laminated argillaceous deposits of the Penarth Group of Late Triassic age which include the Westbury and Lilstock Formations. To the east, there is pyrite-bearing overconsolidated clay deposits including Gault Clay of Cretaceous age and London Clay of Eocene age. These formations underlie major conurbations of England as well as the transportation networks that connect them.

These mudrock deposits occur as weak rock-like and overconsolidated soil-like deposits, typically with a significant calcite and pyrite content. Although they may have appropriate engineering properties, under certain conditions they are susceptible to rapid atmospheric degradation due to the oxidation of reactive pyrite following exposure (Figure 13). The degradation can have serious consequences for construction, particularly those involving earthworks. Potential deleterious implications not only include the development of chemically aggressive ground conditions (Reid et al., 2005) but also deterioration of pavements due to heave and reduced subgrade strength. The reaction rate varies and is difficult to foresee. These conditions can develop rapidly during construction in periods of adverse weather, where they may be observed and remediated. Under favourable construction conditions, they may not be suspected or observed but can develop following construction, necessitating disruptive and costly repair works to pavements and replacement of deteriorated construction material in the future.

Due to uncertainties and often lack of experience and understanding of the potential consequences arising from the degradation of pyritous subgrade, the need for long-term mitigation measures within the road design may not be considered. Furthermore, the early-stage signs of reaction may be missed during the construction period, preventing early intervention.

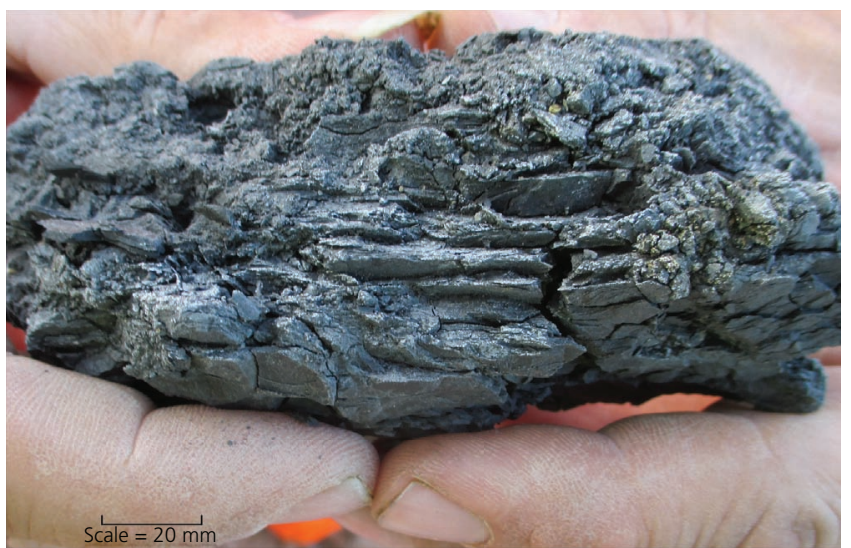

Figure 13. Pyrite 'bloom' due to rapid weathering and iron sulfate development disrupting the fabric in Westbury Mudstone 


\section{The assessment of ground conditions for highway development}

Assessment of ground conditions and determination of subgrade suitability focuses on the determination of immediate groundbearing characteristics in terms of stiffness from which an assessment of long-term bearing characteristics is produced. These parameters are determined by in situ testing of prepared formation under favourable weather conditions. Samples are also tested to establish their sensitivity to changes in moisture conditions from which the long-term bearing characteristics are predicted. An assessment of the potential for deterioration tends to be overlooked, which can pose serious implications when pyritebearing materials are concerned.

The likelihood of aggressive ground conditions and degradation of ground material may be assessed in advance of construction based on thorough review of available ground records and a carefully programmed ground investigation with appropriate material assessment and testing. The description, testing and recognition of weathering in argillaceous deposits enable assessment of the implications posed by oxidation of pyrite and formation of sulfate minerals. The process is managed by geotechnical ground assessment starting with preliminary studies to assess the likelihood of deleterious ground conditions and concluding with derivation of characteristic geotechnical ground parameters for design of construction (see Figure 14). This allows the designer to anticipate the likely engineering behaviour of the material under the likely construction conditions and manage the risks involved with difficult ground conditions that may be encountered during construction.

Pyrite occurs in a variety of forms. In well-indurated deposits, pyrite tends to occur as large recognisable, well-developed, often cubic crystals with a very distinctive brassy yellow colour and metallic lustre (Figure 3). In the less well-indurated deposits, pyrite typically occurs as irregular grains or framboids (Figure 2) and infrequently as less well-developed clusters of interpenetrating cubic crystals (Figure 6). It also occurs in veinlets, as nodules or lenses, or as a replacement deposit in fossils. These can be widely and erratically distributed through soils and rocks, which make it difficult to detect and to estimate the concentration of pyrite in a material.

The recognition of sulfur-bearing minerals in hand specimens of fine-grained deposits requires magnification, as these minerals tend to occur in a finely disseminated form or as microscopic framboids not discernible by eye. Moreover, rather than occurring as goldcoloured crystals, these are usually a dark green-grey to bronzegrey colour. Identification is also hampered by the difficulties posed by making thin sections necessary for petrographic examinations; therefore, the more sophisticated electron microscopy is often preferred, and identification by these methods is a skilled operation.

Characteristic factors indicative of the possible presence of pyrite include
- dark-coloured (grey or dark grey), organic-rich mudrock, calcareous mudrock or clay

n presence of finely disseminated gold and dark green-grey to bronze-grey-coloured crystals often along partings or discrete lenses

- orange-brown and brown staining or precipitates at exposed surfaces or associated with seepages

- sulfurous odour when the rock is hit or scratched

- presence on surfaces of clear or white-grey crystals which it is possible to scratch with a fingernail or of a white surface coating when the material is dried.

Due to the difficulties posed in the visual identification of deleterious components, the assessment of dark-coloured mudrocks, clays and limestone also necessitates testing for the presence of pyrite. Current guidance (BRE, 2005; Reid et al., 2005) recommends that when determination of oxidisable-sulfide (assumed as pyritic) returns values greater than $0 \cdot 1 \% \mathrm{~S}$, then it is likely that pyrite is present.

During the natural process of weathering, the most notable change that will occur to grey deposits is a colour change caused by the oxidation of iron pyrite minerals developing a brown with yellow and orange discolouration. The colour changes are influenced by the hydration states of the iron oxide and hydroxide products of pyrite oxidation. With the presence of calcite in the marine deposits, discolouration is often accompanied by precipitation of granular saccharoidal selenite crystals, often mistaken for sand (Figure 7). These simple colour differences and chemical precipitates are indicative of chemical changes and form a visual basis of assessment of ground material.

The oxidation process requires oxygen catalysed by water. In the surface environment, this is initially provided by flow of oxygenated surface water along discontinuities, or through zones of preferential groundwater flow. This will tend to act progressively, increasing the extent of the oxidised zone and the process may be driven by ingress of oxygenated waters into near surface unsaturated deposits (which may have dried) and ground affected by shallow movement. Under these conditions, the rock or soil mass oxidises to a brown colour. This occurs more rapidly in more permeable sandy deposits than in clay deposits of lower permeability. Gypsum, represented by its crystalline form selenite, is commonly found along fissures, joints and in lenses of cemented nodules where iron oxide staining occurs, ahead of the oxidation front (Figure 15). When ground is permanently saturated with little oxygenated water flow, the oxidation process is greatly restricted and the chemical alterations and colour changes associated with weathering are arrested. But, the deposits may have joints and fissures caused by physical weathering and changes brought about by construction and dewatering which may result in rapid oxidation progressing along discontinuities. 
Geotechnical Research

Volume 2 Issue 3
The benefits of a granular interface over

pyritic subgrade

Czerewko and Cross

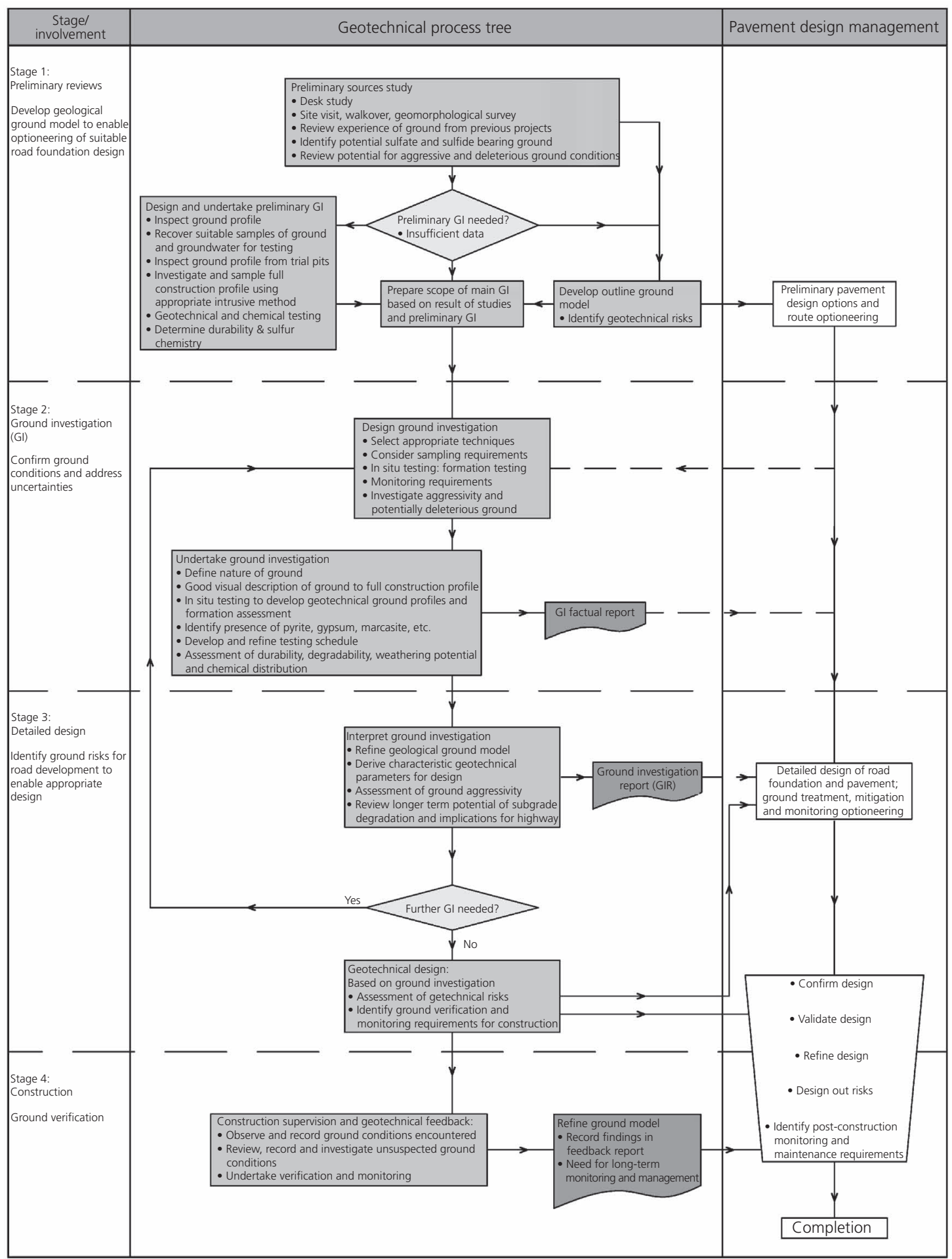

Figure 14. Decision chart for management of geotechnical risk and investigation of potentially aggressive ground 
The benefits of a granular interface over

pyritic subgrade

Czerewko and Cross

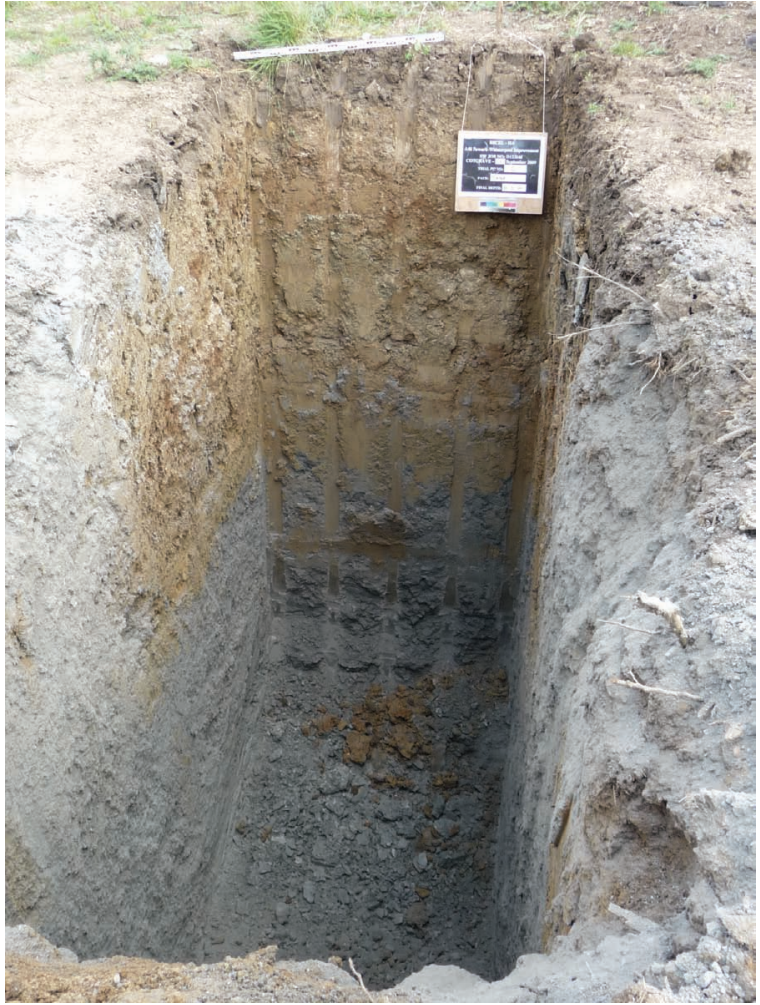

Figure 15. Pyrite oxidation front observed as the clear colour change in Lower Lias mudstone
Therefore, comprehensive assessment and identification of potentially aggressive and deleterious ground conditions may be carried out by a combination of techniques, including

- inspection of the in situ ground conditions

- inspection of sample material recovered from boreholes

- selective chemical testing to determine sulfur species and calcite presence.

The development of weathering associated with pyrite oxidation and precipitation of sulfate minerals may be recognised in vertical examination of the recovered or exposed ground profile as described previously and where possible divided into 'significant' and readily discernible ground horizons based on chemical characterisation to assist the design process (Figure 16). The weathering sequence observed in geological deposits, particularly mudrocks, will tend to exhibit discernible chemical changes that affect the colour along with physical changes that affect the fabric and integrity of the material.

The weathering transition zone is one area where sulfate minerals are likely to occur at or near to likely highway formation levels. The lower levels of the weathering zone in soils with high sulfur contents commonly contain sulfates resulting from oxidation of sulfide minerals. Sulfate minerals tend to be leached from the upper few metres of ground due to surface water and are typically concentrated at the base of root zones indicating the limit of water infiltration. Below this depth, the degree of weathering drops off

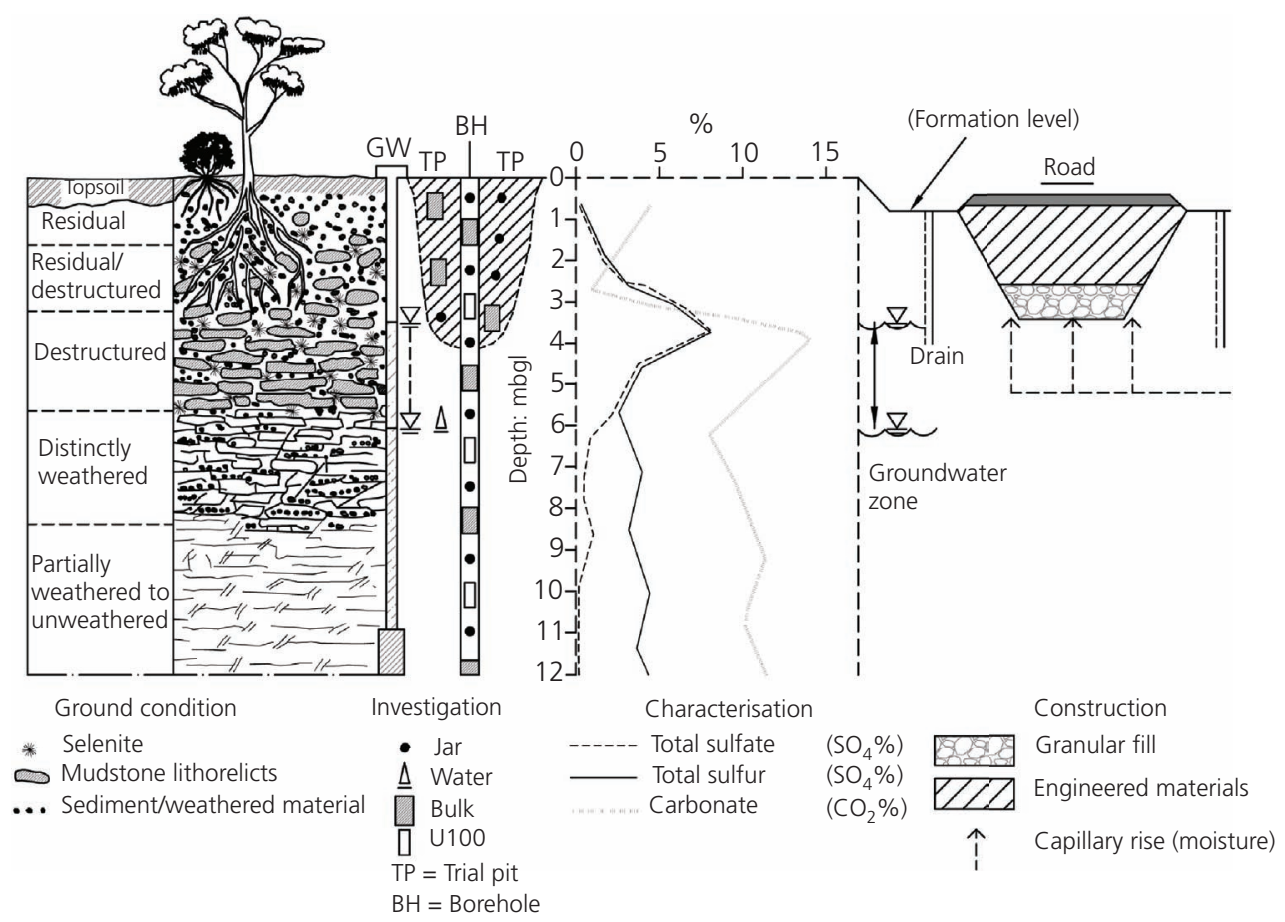

Figure 16. Example of ground characterisation for highway development over pyritic ground 
sharply with decrease in sulfate and increase in sulfide content. This zone may also include evidence of desiccation due to shrinkswell or vertical contraction cracks.

A well-planned ground assessment process should include a review of ground conditions and implications for highway development and provide advice to the pavement designer at all stages of investigation and review. The issues should be recognised and addressed during the ground investigation as outlined in Figure 14, to provide advice for design and mitigation measures. A good visual description of ground to the full depth of construction should form the starting point for any assessment of potentially aggressive ground conditions. This may enable identification of local concentrations of hazardous minerals such as pyrite and gypsum or allude to their presence by colour changes caused by weathering. Although laboratory testing will give precise values for the concentration of chemical constituents at particular locations, they will not be fully representative.

Selection of material for laboratory trials and testing should focus on the earthwork zone but also evaluate the underlying lithology which may be affected by the construction activities in terms of stress relief, disturbance and impact on the groundwater regime. Although sulfate minerals can be present, sulfide minerals may predominate at greater depths where oxidation has not occurred. Exploratory investigations depend on the size of a project and complexity of the geology. No fixed rules can be given for the depth and spacing of exploratory holes; this will depend on the scale of each scheme, specific circumstances of each site and the amount and quality of existing information. Detailed guidance for investigations is provided in Eurocode 7 (Annex B of BS EN 1997-2:2007 (BSI, 2007)) and BS 5930 (BSI, 2015). This should be used for guidance and not as a rule, and the designer is responsible for determining the depth and spacing of exploratory holes required to provide sufficient information for design and geotechnical risk management for the proposed works.

It is important that the positions of exploratory holes are staggered about the centreline of the highway to ensure sufficient transverse coverage of the site in development of the ground model. Boreholes must be deep enough to penetrate well below the bottom of cuttings and any made ground affecting the road or structures. It is good practice to allow for some variation in the road alignment, both horizontal and vertical during the ground investigation. A spacing of between 20 and $200 \mathrm{~m}$ should be considered for location of exploration points and decision for spacing of exploratory locations based on the complexity of anticipated ground conditions following desk study review and preliminary investigation. Ground samples should be taken at intervals of 1 to $2 \mathrm{~m}$ but ensuring that at least one sample is included from every obvious change of strata. A suitable mass of material should be recovered using the most appropriate method for the soil type, and samples should be retained and stored in a suitable manner to prevent deterioration, ensuring that the integrity of the material is maintained for testing (see BRE (2005) and Reid et al. (2005) for further details).
Samples of groundwater should also be collected for testing when encountered, and stored in the appropriate manner described in TRL 447 (Reid et al., 2005) and BRE SD1 (BRE, 2005). Selection of material for testing should consider variation of ground conditions identified by visual description, and samples should be tested to define strata and determine characteristic values of sulfur species. Where concentrations vary widely, a representative data set may need to consider between five and nine results for each strata, but for larger sites such as defined by highway projects, ten or more results for each separate strata identified are desirable for determination of characteristic values. Further guidance may be found in BRE SD1 (BRE, 2005).

\section{Benefits provided by granular construction layers for road foundations}

The inclusion of a granular capping in road construction was required under HD 25/94 (HA, 1994), but changes brought about by IAN 73/06 (HA, 2009a) strongly favour the use of HBM to provide the required foundation strength and leave the inclusion of a capping layer as a restricted option. Although current guidance suggests that a capping layer may be beneficial for plant to lay the sub-base and achieve good compaction over soft ground, it also states that the structural contribution of capping material with low layer stiffness values is limited when compared with the stiffness of sub-base materials used for foundations which rely on HBM construction. The design guidance does not appreciate the implications posed by pyrite weathering and therefore the benefits offered by a granular capping layer are not recognised. Due to the drive towards cost savings with rationalised design favouring the more rigid HBM, provision of suitable flexible capping is overlooked.

A granular layer distributes load from the road through a framework of grains comprising material of suitable crushing strength and durability, which serves to strengthen weak subgrade and provides adequate support to the applied traffic loads. Conversely, the base of the granular layer is capable of dissipating and managing the stresses produced by the precipitation and growth of sulfate minerals. The granular layer acts to cushion the road construction as it enables unobstructed precipitation in the voids between the gravel size fragments, reducing potential crystallisation stresses which are consequential under confined conditions found at hard impenetrable construction interfaces, for example, the base of HBM. Also, the large pore size reduces potential for capillary rise and prevents the access of sulfaterich pore waters into the road layers, avoiding destructive crystallisation of mineral products.

Granular layers are used in road foundation for a number of reasons other than traditional capping; these are grouped in Series 600 (HA, 2009b) under 'Selected Granular Fills' which include material grading suited for starter layers over poor or wet ground, capping, drainage layers and materials suited as capillary breaks. Capping layers have traditionally been used in road construction over weak subgrade to provide adequate strength to support the 
road. Therefore, the capping has been used to supplement the sub-base as a more cost-effective foundation element. When the water table is high, a granular aggregate starter layer would also be included as a drainage blanket. Under high groundwater conditions, capillary rise is supported, and the granular starter layer would also function as a capillary barrier to minimize the exposure of the pavement to any detrimental effects.

Each of the options uses granular materials of suitable strength and durability that conform to grading and abrasion resistance requirements specified in Series 600 (HA, 2009b). The purpose of a granular interface layer is to serve as a protective barrier to prevent deterioration of the pavement layer and subgrade during construction and thereafter from highway traffic, surface water infiltration or the effects of positive water pressures in areas of cut or where construction at grade takes place in areas of high groundwater. Additionally, these granular barriers have served to prevent migration of potentially deleterious ground chemical species such as sulfate and chloride ions or other species that may be naturally present in the subgrade or made ground or arise as consequence of the construction, particularly with pyrite oxidation. The mobile sulfate in solution may react adversely with cementitious pavement material, or precipitate on the underside of the pavement or within the pavement causing differential uplift and pavement fracturing.

Where embankments are formed over areas of shallow groundwater, water will tend to travel long distances and rise to considerable heights of up to $10 \mathrm{~m}$ or more in clay soils due to capillary rise. Where ground or fill materials include a pyritic or gypsum component, weathering and upward migration of sulfate ions will prove destructive to the embankment and road construction.

In ground material, capilliarity describes the ability of a dry soil, aggregate or rock to draw water to elevations above the phreatic line, thus enabling a free-draining mass to retain water above the water table (Lambe and Whitman, 1979). Flow in the capillary fringe will develop due to pressure gradients that originate from evaporation or freezing of groundwater. The height of capillary rise is taken as a function of both the pore size of the granular material and the contact angle between the water and solid. However, it should be borne in mind that a granular medium will have a range of pore sizes and shapes, and the groundwater is not typical and will have a density and surface tension less than optimum due to dissolved ions. Since soils and compacted aggregates will have a range of void sizes, it would be reasonable that it could support a number of capillary heads. Therefore, it is taken that the height of water column that can be supported must depend on the void size that is most effective.

The effective pore diameter is defined by Holtz and Kovacs (1981) as $10 \%$ of the effective grain size and is taken as the $D_{10}$ particle size determined by grading. The height of capillary rise is a function of both the pore size and contact angle of the material and the surface tension effects of the fluid (Barnes, 2010). The cleanliness of the water will affect the height of capillary rise for the fluid and it is found to be much less for polluted water. Therefore, the effectiveness of a granular interface in restricting the rise of contaminated water containing sulfate species depends on the grain packing of constituent grains. This is defined by the void ratio and effective pore diameter and can be determined according to the relationship given in Equation 3 (from Terzaghi and Peck, 1967)

3. $h_{\mathrm{c}}=\frac{C}{e D_{10}}$

where $h_{\mathrm{c}}$ is max height of capillary rise in mm related to effective pore size; $C$ is constant for clean water, $10-50 \mathrm{~mm}^{2}$ (use lower values for sulfate pore solution); $D_{10}$ is effective size in $\mathrm{mm}$; and $e$ is void ratio - for coarse sand and coarse gravel typically $0 \cdot 27-0 \cdot 35$.

Generally, in open gravels, the capillary rise tends to be negligible, typically between 10 and $80 \mathrm{~mm}$, whereas in clay, it will be considerable, ranging between a few metres to tens of metres.

The relationship presented in Equation 3 indicates that selected natural or processed geomaterial having a uniformly graded granular composition, such as coarse sand and gravels or singlesize crushed rock typical of starter layer materials that have large pore areas, can be highly effective as capillary barriers when construction is located over shallow groundwater. The material needs to be open-textured thus consisting of a narrow particle size range to ensure an open pore structure. Well-graded sands and gravels are not always suitable capillary barriers as the tight grain packing will fill space between larger fragments with finer size components enabling capillary rise of water needing much thicker layers to prevent pore fluid migration.

In areas of high groundwater and pyrite-bearing subgrades, consideration for a capillary barrier is essential. Suitable material should be selected for the construction of granular separators to create barriers capable of preventing sulfate-rich groundwater contacting with the pavement construction layers. The selected material should be uniformly graded and of appropriate durability to prevent fragmentation under the imposed construction loads for at least the life period required in the design. Typical suitable materials included within Series 600 (HA, 2009b) would include (but are not limited to) a Class 6C uniformly graded starter layer (Figure 17) or a coarse Class 6F2 capping layer (Figure 18). These materials would generally originate from a local source and therefore the designer would have to ensure that the layer would be of sufficient thickness commensurate with the effective pore diameter to arrest capillary rise. Typically, the height of capillary rise for open-graded coarse sands and gravels is estimated to be less than $200 \mathrm{~mm}$. Therefore, a granular interface layer comprising of a uniformly graded aggregate should be constructed with a final thickness of 
The benefits of a granular interface over

pyritic subgrade

Czerewko and Cross

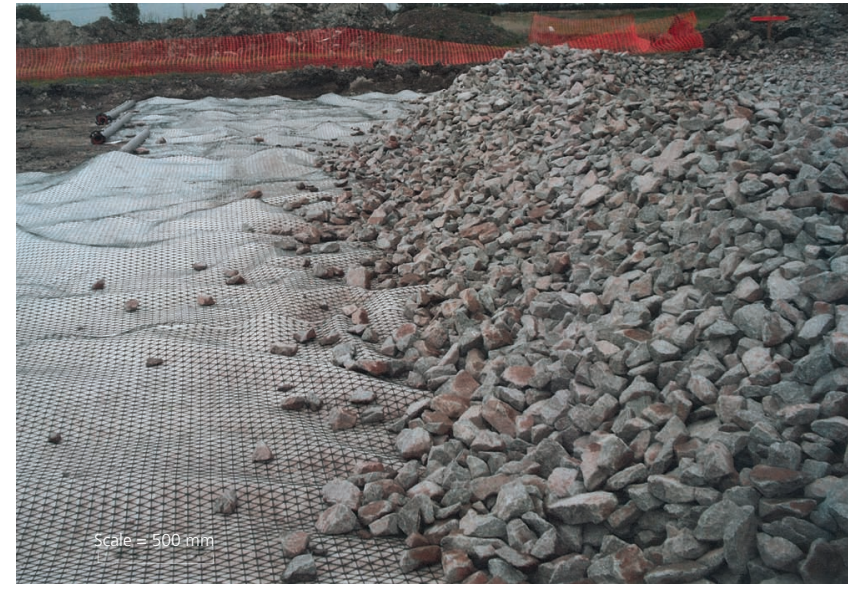

Figure 17. Uniformly graded granular starter layer

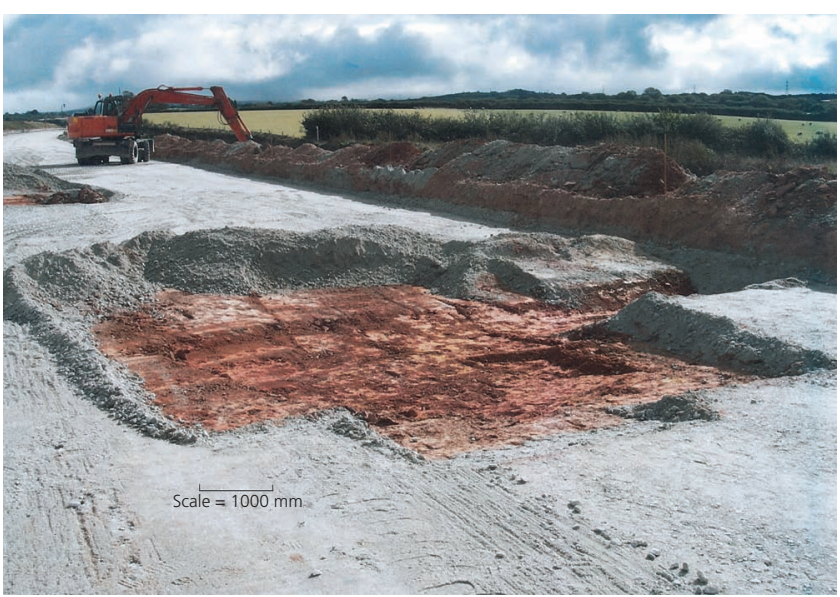

Figure 18. Coarse uniformly graded capping layer

approximately $300 \mathrm{~mm}$, which includes a margin of safety between average and maximum capillary rise in granular material.

\section{Case studies}

Location 1: A1(M) Alconbury

Construction of the A1(M) highway near Alconbury in Cambridgeshire comprised a dual four-lane carriageway and hard shoulder (Figure 3). Construction was undertaken between summer 1996 and spring 1998. Various sections comprised fully flexible or flexible composite designed to a high stiffness that relied on HBM construction of the sub-base. Construction consisted of two or three CBM sub-base layers formed directly onto prepared subgrade of virgin ground at-grade and also over areas of broken out former stretches of the A1 carriageway. A thin bedding layer of sand separated the sub-base and subgrade. The CBM road base layer was generally precracked with transverse cracks formed at $3 \mathrm{~m}$ intervals in all the flexible composite pavement sections.
The ground conditions comprised Glacial Till that was largely derived from the underlying deposits forming the higher areas of ground overlying Oxford Clay Formation. The Glacial Till was described as very stiff sandy clay with much gravel, including chalk, mudstone and flint. The Oxford Clay consisted of a stiff grey to green grey closely fissured clay becoming extremely weak mudstone. Typically, the upper 3-6 m was recorded as weathered except where overlain by Glacial Till, where it was recorded as fresh to slightly weathered. Investigations had recorded that locally, the Glacial Till and Oxford Clay contained crystals of selenite. The groundwater monitoring data recorded seasonal variations in the levels recorded with a range to within 0.3 and $3.0 \mathrm{~m}$ below ground level and extending to the base of the instrument response levels between 10 and $20 \mathrm{~m}$ below ground level. The geotechnical properties recorded for the Oxford Clay subgrade are summarised in Table 1.

Chemical testing was limited to the determination of watersoluble sulfate, with recorded values typically between $<0 \cdot 2$ and $1 \cdot 89 \mathrm{~g} / \mathrm{l}$, with $\mathrm{pH}$ values typically between 7 and $7 \cdot 8$, providing a classification for buried concrete design of Class 1-Class 2 based on the then current guidance (BRE, 1991). Potential implications for construction such as aggressive ground conditions towards concrete and cementitious material and potential for heave due to remobilisation of existing sulfate were not identified in the ground interpretation and design reports.

On completion of the highway works, a deflectometer survey concluded that the pavement construction complied with deflection test requirements. Not long after, transverse cracks and undulations at the road surface were noted in sections of the flexible composite pavements in areas generally formed over the virgin subgrade. Condition surveys were carried out during 2003 and 2004 and recorded areas affected by significant pavement cracking that were severely impacting on the road function. Subsequent pavement investigation revealed debonding and significant cracking within the asphalt bound road layers (Figure 19) and $<30 \mathrm{~mm}$ of differential movements were recorded at the sub-base over presplit cracks (Figure 20). During periods of heavy rain, water seepage had been noted precipitating a clay residue with an occasional white discolouration.

During 2006, an investigation was carried out in a select area situated in the hard shoulder affected by surface defects which had been recently remediated as part of the routine maintenance programme. The intrusive investigation comprised two machine excavations to expose the road construction layers for inspection and sampling of the subgrade extending from the base of the excavations using portable dynamic window samplers for recovery of natural ground material.

The exposed road construction comprised $200 \mathrm{~mm}$ of asphalt pavement over $500 \mathrm{~mm}$ of combined CBM sub-base. The subbase layers consisted of a stiffer upper coarse aggregate CBM 


\begin{tabular}{|c|c|c|c|}
\hline \multicolumn{2}{|l|}{ Property } & $\begin{array}{l}\text { Weathered clay/mudstone } \\
\text { (number of determinations) }\end{array}$ & $\begin{array}{l}\text { Fresh calcareous siltstone } \\
\text { (number of determinations) }\end{array}$ \\
\hline Material description & & $\begin{array}{l}\text { Firm brown to very stiff } \\
\text { greenish grey silty clay }\end{array}$ & $\begin{array}{l}\text { Weak and medium strong } \\
\text { light brown calcareous siltstone }\end{array}$ \\
\hline Moisture content, w: \% & & $12-58(32)$ & 10-22 (3) \\
\hline Liquid limit, $w_{\mathrm{L}}: \%$ & & $24-83(316)$ & - \\
\hline Plastic limit, $w_{\mathrm{p}}: \%$ & & $14-32(298)$ & - \\
\hline Plastic index, $I_{p}: \%$ & & $8-55(298)$ & - \\
\hline \multirow[t]{2}{*}{ UUTx - undrained shear strength } & $0-1 \mathrm{~m}$ & $25-100(5)$ & - \\
\hline & $1-10 \mathrm{~m}$ & 28-292 (44) & \\
\hline $\mathrm{C}_{\mathrm{u}}: \mathrm{kPa}$ (for depth range in $\mathrm{mbgl}$ ) & $10-20$ m & $82-570(38)$ & \\
\hline \multirow[t]{2}{*}{ CUTx - effective stress } & $c^{\prime}: k N / m^{2}$ & $1-6(36)$ & - \\
\hline & $\phi^{\prime}:$ degrees & $21-25(36)$ & - \\
\hline UCS: MPa & & - & $25 \cdot 3-49 \cdot 5(6)$ \\
\hline
\end{tabular}

UUTx, unconsolidated undrained triaxial test; CUTx, consolidated undrained triaxial test; UCS, unconfined compressive strength.

Table 1. Summary of available records from main phase and supplementary ground investigations material characterisation testing of Oxford clay and calcareous siltstone units

over a less stiff coarse sand and fine gravel CBM layer formed onto a sand blinding layer of less than $20 \mathrm{~mm}$ over the subgrade.

The subgrade comprised $<600 \mathrm{~mm}$ of Glacial Till with inclusions of the underlying strata overlying variably weathered Oxford Clay. The recovered Oxford Clay comprised weathered material containing decayed rootlets with zones of less weathered material believed to have been caused by previous vegetation cover at the site. The presence of significant quantities of saccharoidal selenite was observed in the Glacial Till as well as the Oxford Clay extending from below the interface with the road foundation (Figure 21).

Chemical test results on recovered material were scheduled to determine the distribution of sulfur species extending from below the underside of the road. The test results (Table 2) indicate a

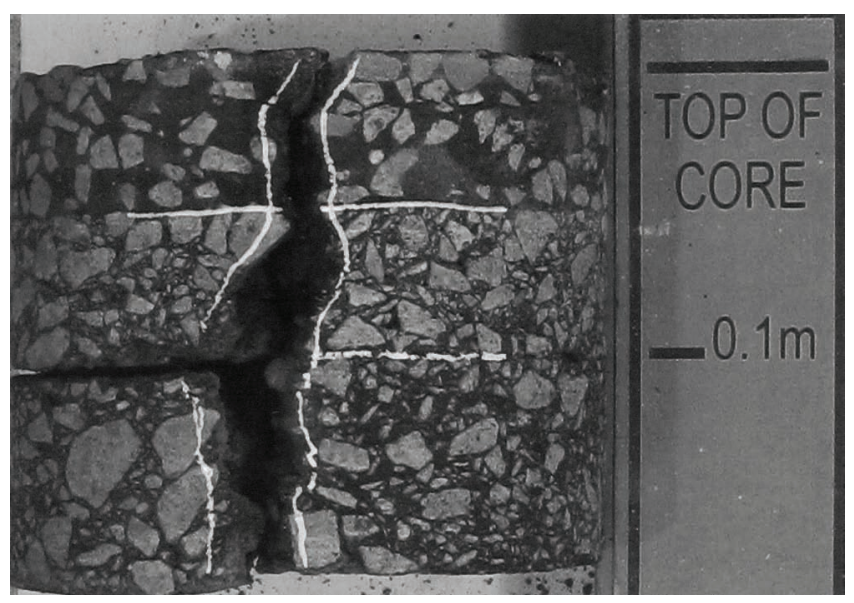

Figure 19. Cracking and debonding in asphalt road layers significant proportion of gypsum extending from the underside of the formation. The chemical test results for samples of CBM material suggests typical sulfate content values accounted for by the gypsum component of the cement binder. The test data for the subgrade material indicate that the sulfur species are dominated by the presence of sulfate, confirming a predominance of gypsum at the expense of pyrite weathering. The remaining sulfur was postulated to be potentially unreacted sulfide in the form of pyrite, generally occurring within the less weathered zones.

Observation of the Oxford Clay profile indicated that selenite was concentrated along distinct weathered zones formed along bedding planes and vertical fissures (Figure 22). The base of the weathered zone in the Oxford Clay was observed in the recovered samples at a depth between 2.5 and $3 \mathrm{~m}$ below ground comprising

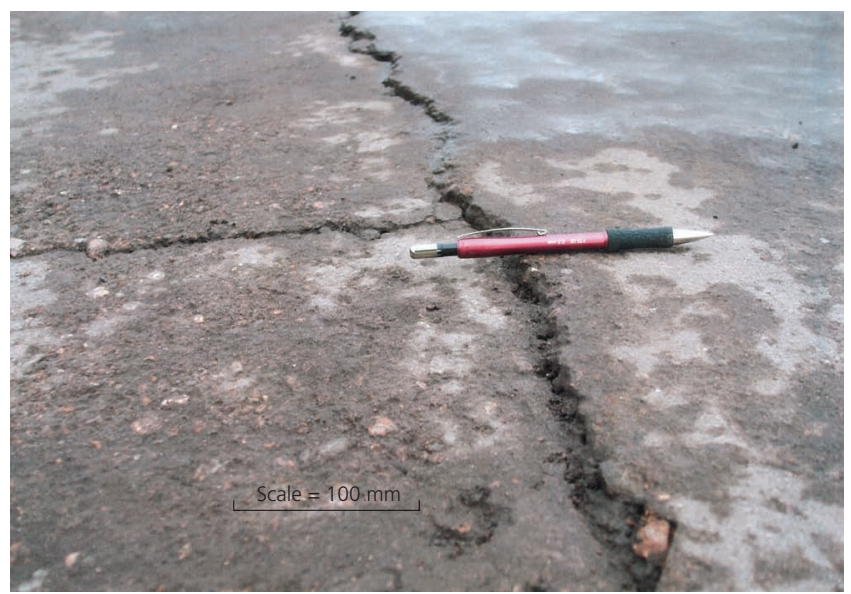

Figure 20. Heave and cracking within precracked sub-base 
The benefits of a granular interface over

pyritic subgrade

Czerewko and Cross

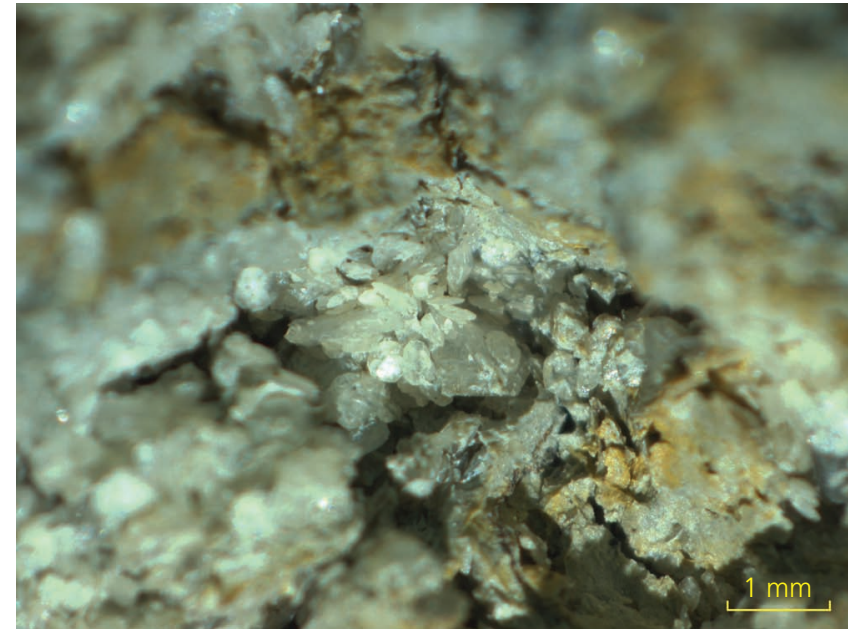

Figure 21. Fine selenite concentration in Glacial Till underlying the sub-base

mid-grey closely fissured clay containing decayed rootlets, listric shear planes and abundant 'swallowtail' selenite crystals (Figure 23) typical of an established root desiccation zone. The calcium carbonate content was recorded between $15 \%$ and $28 \%$, which would account for the source of calcium for selenite formation following pyrite oxidation. The modified plasticity index values for the Glacial Till and Oxford Clay were between 16\% and 22\%, indicating a material of low to medium volume change potential.

Clay deposition was recorded at the road surface adjacent to cracks following heavy rainfall, suggesting infiltration and interaction with the subgrade. On drying, the clay precipitate developed white streaks suggesting the present of selenite efflorescence. The presence of weathered subgrade and gypsum at the immediate subgrade interface are believed to be the result of pyrite weathering and the likely source of the observed heave exacerbated by surface water infiltration. The presence of vertical fissures in the subgrade weathered zone enables infiltration by surface water and remobilisation and reprecipitation of sulfates. Remediation included replacement of the affected pavement and

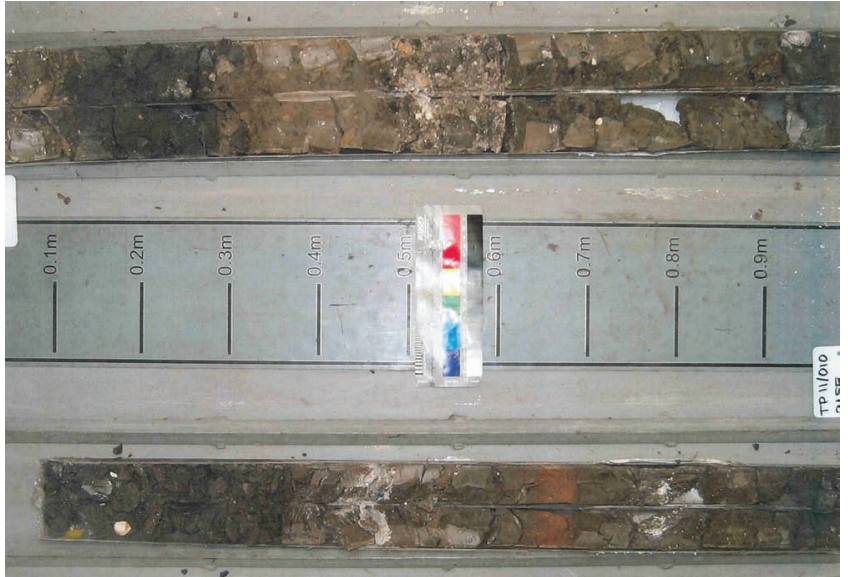

Figure 22. Alternating weathering zones in Oxford Clay attributed to former root systems

formation of drainage cuts to address the site drainage issues and control remobilisation of ground sulfates. Regular monitoring carried out by the maintenance engineer since completion of the remedial works completed during 2006-2007 has not recorded any further movement.

\section{Location 2: A63 Melton}

The road improvement scheme included construction of a gradeseparated junction and associated link roads over a $1.5 \mathrm{~km}$ section of the A63 dual carriageway west of Hull, between Melton and Ferriby, which was originally built during the 1960s (Figure 4). The groundworks commenced in June 2004 and was largely completed by April 2007 for traffic use. The pavement foundations were designed in accordance with HD 25/94 (HA, 1994) with provision of various capping thicknesses over sections of poor subgrade.

The site is partially located over a prominent north-south trending ridge of Jurassic Age Ancholme Group mudstone that comprises stiff grey gravelly clay to very weak dark grey mudstone which is weakly calcareous and includes fossil shell debris. The geotechnical properties recorded for the Ancholme Clay during the

\begin{tabular}{|c|c|c|c|}
\hline Depth (m below road level) & Material & Acid-soluble sulfur (ASS - \%S) & Total sulfur (TS - \%S) \\
\hline 0.6 & Fine $C B M$ & $0 \cdot 18-0 \cdot 20$ & $0 \cdot 20$ \\
\hline $0.62-0.82$ & Glacial Clay with gravel & $0 \cdot 14-0 \cdot 18$ & $0 \cdot 21$ \\
\hline $0.82-1.05$ & Glacial Clay with gravel & $0.53-0.76$ & $0.61-0.81$ \\
\hline $1 \cdot 2-1 \cdot 3($ TP1 $)$ & Glacial Clay with gravel & $1 \cdot 16$ & $1 \cdot 23$ \\
\hline $1 \cdot 37-1 \cdot 50($ TP2) & Weathered Oxford Clay & $0 \cdot 10$ & 0.55 \\
\hline $1 \cdot 9-2 \cdot 1($ TP1) & Weathered Oxford Clay & $4 \cdot 53$ & $4 \cdot 50$ \\
\hline $2 \cdot 5-2 \cdot 9(\mathrm{TP} 2)$ & Weathered Oxford Clay & 0.79 & 0.84 \\
\hline
\end{tabular}

$\%$ S, determined as percent sulfur

Table 2. Chemical test data for CBM and subgrade below the A1(M) carriageway. 
The benefits of a granular interface over

pyritic subgrade

Czerewko and Cross

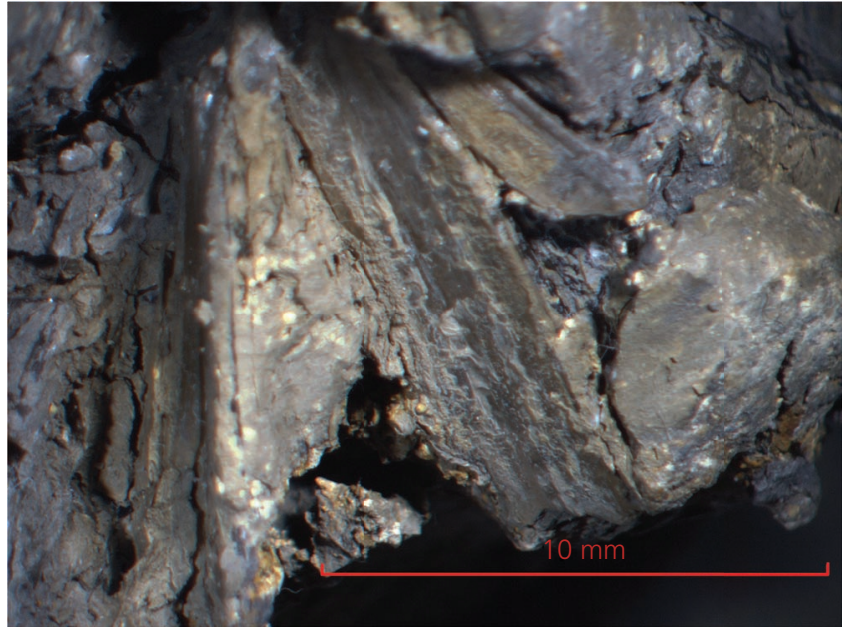

Figure 23. Selenite crystals concentrated at the base of the root desiccation zone

design investigation are summarised in Table 3 together with data recorded from samples of weak mudstone sampled and tested during the construction phase. The Jurassic Age deposits are flanked to the east and west by younger Cretaceous chalk deposits and overlain by glacial deposits with a thin topsoil cover.

Design stage ground investigations confirmed the presence of Ancholme Clay underlying the Ferriby Chalk, or underlying glacial deposits where the Ferriby Chalk was absent. Therefore, it was anticipated that the Ancholme Clay would be at subgrade depth and exposed to surface conditions over a distance of approximately $110 \mathrm{~m}$ in a section of new construction formed in cutting for a link road. Description of the material alluded to the presence of pyrite in the Ancholme Clay and was confirmed by chemical testing recording total sulfur contents of between $0 \cdot 92 \% \mathrm{~S}$ and $2 \cdot 6 \% \mathrm{~S}$.

A characteristic value for total potential sulfate of $4 \cdot 95 \% \mathrm{SO}_{4}$ was adopted deriving a Design Sulfate Class DS-4 and Aggressive Chemical Environment for Concrete of AC-4. The values were reduced to DS-2 and AC-2 for concrete not exposed to disturbed ground conditions. Considerations for aggressive conditions towards concrete were anticipated and designed for accordingly. The subgrade foundation assessment carried out for the Ancholme Clay subgrade established that the materials' long-term characteristics were poor and therefore necessitated inclusion of a $600 \mathrm{~mm}$ capping layer.

The deposits of granular Glacial Till surrounding the exposed Ancholme Clay were deposits of hydrogeological significance. Gravel-filled channels had been formed through the Ancholme Clay surface by glacial action allowing water infiltration from adjacent areas of water-bearing granular glacial deposits (Figure 24). Although the design had anticipated the presence of pyritic material and included appropriate design for the earthworks, the rapidity of pyrite oxidation and subsequent deterioration of the mudrock subgrade that was observed following exposure had not been anticipated.

\begin{tabular}{|c|c|c|c|}
\hline \multicolumn{2}{|l|}{ Property } & $\begin{array}{l}\text { Weathered clay/mudstone } \\
\text { (number of determinations) }\end{array}$ & $\begin{array}{c}\text { Fresh mudstone } \\
\text { (number of determinations) }\end{array}$ \\
\hline \multicolumn{2}{|l|}{ Material description } & $\begin{array}{c}\text { Stiff and very stiff brown-grey and grey } \\
\text { gravelly clay - from depths to } 5.0 \mathrm{~m} \\
\text { below lithological interface }\end{array}$ & $\begin{array}{c}\text { Weak laminated grey mudstone - from } \\
5.5 \mathrm{~m} \text { below lithological interface }\end{array}$ \\
\hline \multicolumn{2}{|l|}{ Moisture content, w: \% } & $10-40(38)$ & $10-26(3)$ \\
\hline \multicolumn{2}{|l|}{ Liquid limit, $w_{\mathrm{L}}: \%$} & $59-76(32)$ & $54-62(3)$ \\
\hline \multicolumn{2}{|l|}{ Plastic limit, $w_{P}: \%$} & 23-33 (33) & $25-34(3)$ \\
\hline \multicolumn{2}{|l|}{ Plastic index, $I_{p}: \%$} & $30-48(32)$ & $24-28(3)$ \\
\hline $\begin{array}{l}\text { UUTx - undrained shear } \\
\text { strength }\end{array}$ & $c_{u}: k P a$ & $25-213(15)$ & - \\
\hline \multirow[t]{2}{*}{ CUTx - effective stress } & $c^{\prime}: k N / m^{2}$ & $4-28(6)$ & - \\
\hline & $\phi^{\prime}:$ degrees & $21 \cdot 5-37(6)$ & - \\
\hline \multirow{2}{*}{$\begin{array}{l}\text { Oedometer consolidation } \\
\quad(100-400 \mathrm{kPa} \text { stress range) }\end{array}$} & $m_{\mathrm{v}}: \mathrm{m}^{2} / \mathrm{MN}$ & $0.081-1.069(8)$ & - \\
\hline & $c_{v}: m^{2} /$ year & $0 \cdot 109-2 \cdot 79(8)$ & - \\
\hline \multicolumn{2}{|l|}{ UCS: MPa } & - & $0.86-1.9(3)$ \\
\hline \multicolumn{2}{|l|}{ CBR (lab) } & $2-12(16)$ & - \\
\hline
\end{tabular}

UUTx, unconsolidated undrained triaxial test; CUTx, consolidated undrained triaxial test; $m_{V}$, coefficient of volume compression; $c_{V}$, coefficient of consolidation; UCS, unconfined compressive strength; CBR, California bearing ratio.

Table 3. Summary of main phase ground investigations material characterisation testing of Ancholme Clay and mudrock 
Geotechnical Research

Volume 2 Issue 3
The benefits of a granular interface over

pyritic subgrade

Czerewko and Cross

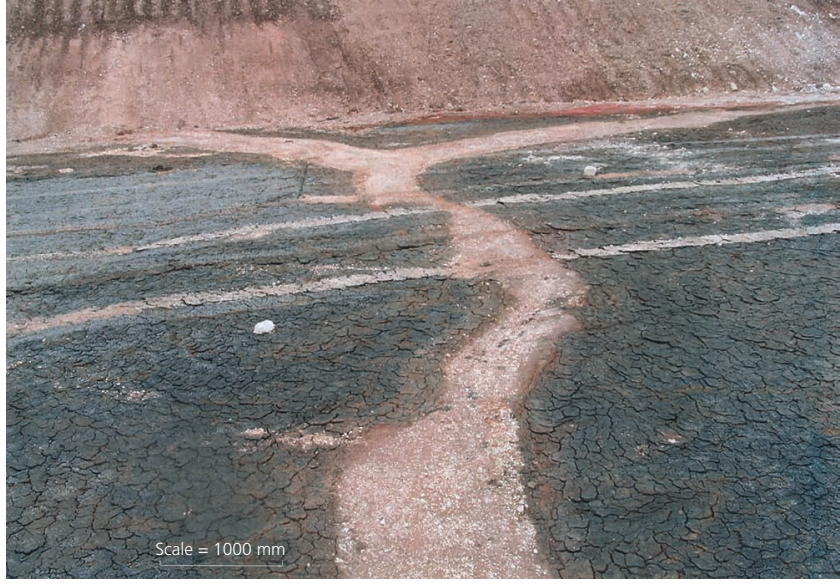

Figure 24. Glacial channels with granular infilling cutting through Ancholme Clay

Soon after completion of the formation preparatory works, deterioration of the exposed surface was noted following a period of heavy rainfall. The previous level surface finish had significantly deteriorated with development of polygonal desiccation cracks with the cuspate edges elevated up to $20 \mathrm{~mm}$ and an extensive white efflorescence cover had developed at the sun dried surface (Figure 25). Further inspection was carried out 3 weeks later following a period of dry weather when the significant development of single and multiple clear and white crystals of selenite up to $16 \mathrm{~mm}$ in length and the brown mineral jarosite were observed at the desiccated ground surface (Figures 26 and 27). Ground excavation identified a variable weathered zone extending down to $3 \mathrm{~m}$ below the Ancholme Clay sub-crop interface, comprising firm mottled light grey and brown clay with occasional lithorelicts of mudstone over stiff grey calcareous clay grading to extremely weak dark grey calcareous mudrock. The depth of weathering

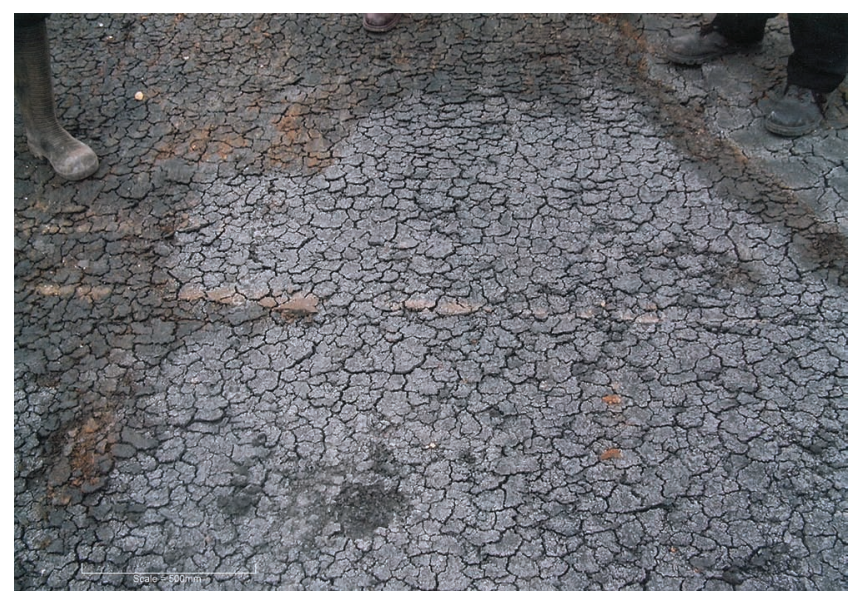

Figure 25. Desiccation and selenite efflorescence cover to cut surface

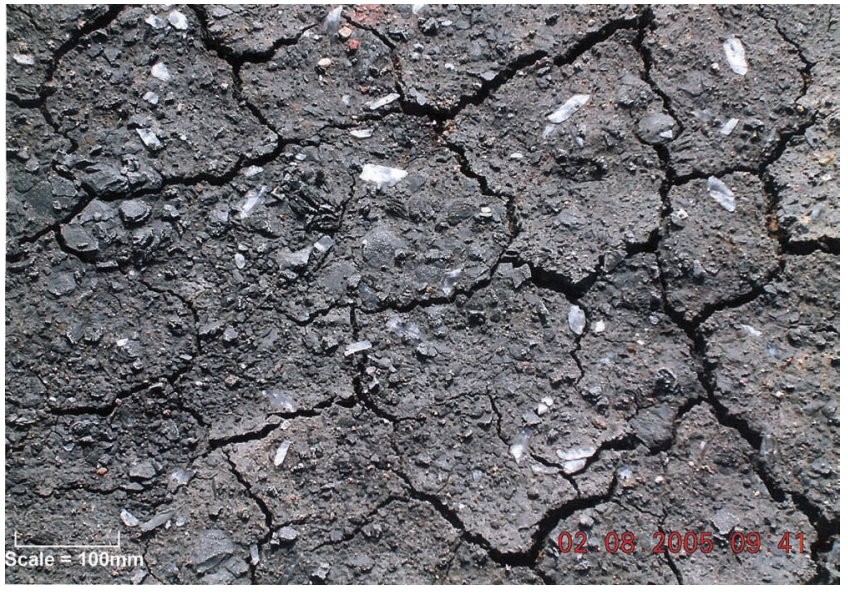

Figure 26. Development of selenite crystals at cut surface

was observed to be deeper adjacent to the trenches of glacial granular material.

Testing of recovered material revealed a concentration of sulfate minerals at the expense of sulfide minerals over a shallow depth extending to approximately $3 \mathrm{~m}$ below the excavation surface, with rapid reversal thereafter (see Figure 28). The presence of framboidal pyrite was confirmed by scanning electron microscopy and chemical testing recorded between 2\% and $3.9 \%$ pyrite in fresh mudstone and calcite content between $2 \cdot 2 \%$ and $4 \cdot 3 \%$. Therefore, further deleterious consequences from pyrite oxidation and selenite formation could not be ruled out.

Further inspections carried out over the following 10 weeks recorded development of well-formed tabular and swallow tail selenite crystals up to $130 \mathrm{~mm}$ in length growing at the exposed stockpile (Figure 29). Further site visits over the following

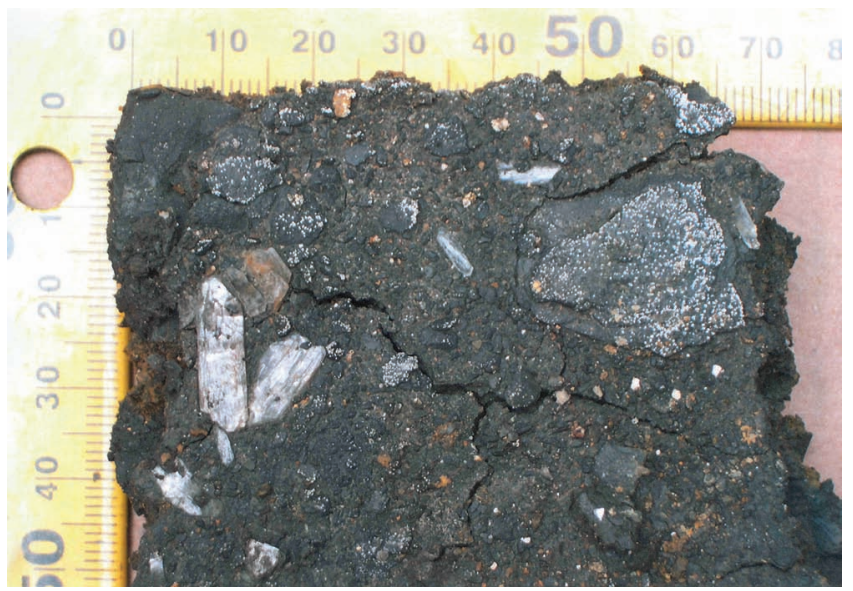

Figure 27. View of selenite crystals and efflorescence development at Ancholme Clay surface 
Geotechnical Research

Volume 2 Issue 3
The benefits of a granular interface over

pyritic subgrade

Czerewko and Cross

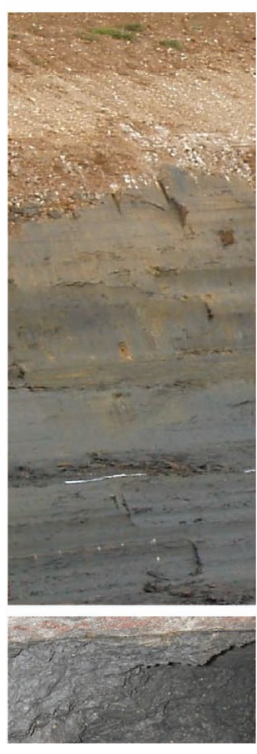

Silty sand with chalk gravel (glacial deposits)

Firm light grey mottled brown and orange clay. (Completely - highly weathered Ancholme Clay)

Stiff grey mottled brown clay with mudstone lithorelicts. (Moderately weathered Ancholme Clay)

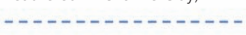

Very stiff dark grey locally discoloured brown clay with tabular mudstone lithorelicts and and ammonite debris containing are disseminated pyrite infill. (Slightly weathered Ancholm Clay)

Very stiff to extremely weak dark

Figure 28. Ground weathering profile recorded through the

Ancholme Clay

3 months did not record any increases in the sizes of the selenite crystal that were observed, although the crystals tended to be thicker and development of interpenetrating twins was evident (Figure 30). Development of the significant quantity of large selenite crystals reaffirmed the potential consequences that could be anticipated from ground heave. Formation of selenite-gypsum from the precursor pyrite and calcite accounts for a theoretical volume change of 53\% according to Cripps and Edwards (1997), with the precipitation of new products not necessarily being at the site of reaction but potentially anywhere along the construction interface, particularly at water discharge points as observed at the stockpiles.

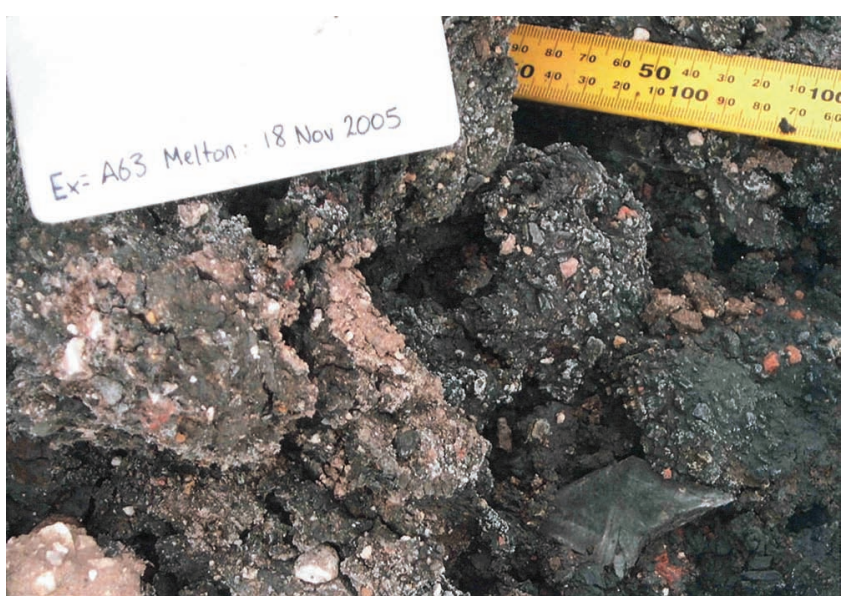

Figure 29. Well-formed selenite crystal growth from stockpile exposure
As a consequence of the study, a $600 \mathrm{~mm}$ flexible inert granular capping to the road and benched side slopes was considered adequate protection against long-term effects from ongoing oxidation. Construction included provision of road filter drains to intersect surface infiltration and inflow of groundwater from adjacent areas to protect the subgrade from further degradation.

During the earthwork period, exposure of the Ancholme Clay material at carriageway sub-formation level was restricted and a $600 \mathrm{~mm}$ weathering protection layer was left in place during the preparatory works. The weathering protection layer was

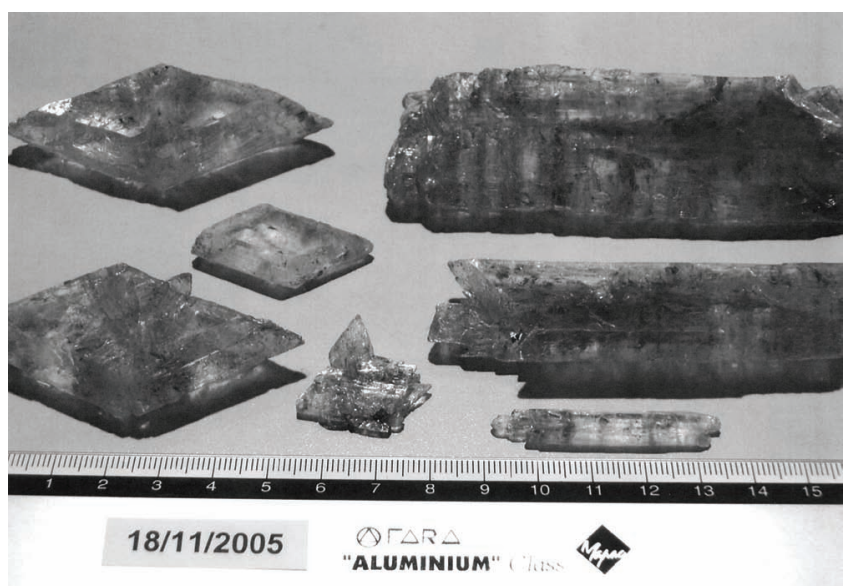

Figure 30. Range of selenite crystal forms recovered from the stockpile surface 
removed immediately prior to construction of the full $600 \mathrm{~mm}$ thickness of capping which was carried out during dry weather to protect against wetting and avoid onset of pyrite oxidation.

The road was completed and opened during autumn of 2006 and regular routine monitoring confirms that it remains unaffected by subgrade degradation to date.

\section{Location 3: A46 Newark to Widmerpool}

This scheme involved the construction of a dual carriageway $28 \mathrm{~km}$ in length to replace a busy section of the arterial A46 trunk road connecting the East and West Midlands (Figure 4). The works commenced in March 2009 and the road was opened to traffic in the summer of 2012 .

The scheme included a $7 \mathrm{~km}$ section located over pyritic Lower Lias deposits of Jurassic Age overlying the transitional pyritic Penarth Beds before passing into the Triassic Mercia Mudstone Group (Czerewko et al., 2011). Following the preliminary phases of ground investigation, the pavement design was carried out in accordance with IAN 73/06 (HA, 2009a) which concluded that the formation level was of sufficient resilience and the design did not include a capping layer. A summary of the geotechnical characteristics determined for the Lower Lias deposits during the ground investigation are presented in Table 4.

Early in the scheme, a section of new construction in an area of Lower Lias escarpment, near Cotgrave Village, raised concerns over instability due to pyrite-bearing mudrocks. The escarpment comprising gently undulating ground with low-lying rounded summits showed signs of slope movement and groundwater discharge. Ground investigation recorded a lithology of mudstone with subordinate limestone of the Scunthorpe Mudstone Group and Barnstone Member. The recorded material comprised weak darkgrey laminated calcareous mudstone when fresh, becoming stiff brown calcareous clay and extremely weak brown calcareous mudstone when weathered. The fabric of the weathered clay was observed to be closely fissured and friable, and the mudstone closely jointed, with development of extensive shallow slip planes accommodating progressive selenite crystal growth (Figure 31 ). The clay and mudstone beds contained calcareous nodules and fossil debris with rare pyrite nodules, cubic pyrite crystal clusters (Figure 32) and pyritised fossil material. Occasional thin limestone beds were recorded. Discrete selenite crystals and clusters up to $80 \mathrm{~mm}$ in size were recovered from damp joint surfaces (Figure 33).

Due the potentially problematic nature of the pyritic material, detailed laboratory studies and field weathering trials were carried out to assess the characteristics of the ground and determine the implications for embankment construction and highway cuts from pyritic material and slip zones (Czerewko et al., 2011).

The pyrite morphology was examined using scanning electron microscopy confirming the presence of disordered pyrite framboids comprising of small octahedral pyrite crystallites in the order of $1-2 \mu \mathrm{m}$ in size (Figure 34). Chemical and mineralogical characterisation of the mudrock recorded $2-3 \%$ pyrite, up to $4.6 \%$ gypsum and between $18 \%$ and $22.3 \%$ calcite. The significant content of unweathered pyrite indicated the potential for further deleterious reaction and material degradation. The high calcite content of the material considered is conducive for acid-base

\begin{tabular}{|c|c|c|c|}
\hline \multicolumn{2}{|l|}{ Property } & $\begin{array}{l}\text { Weathered clay/mudstone } \\
\text { (number of determinations) }\end{array}$ & $\begin{array}{c}\text { Fresh mudstone } \\
\text { (number of determinations) }\end{array}$ \\
\hline \multicolumn{2}{|l|}{ Material description } & $\begin{array}{l}\text { Stiff and very stiff brown grey clay } \\
- \text { from depths of } 0.6-4.6 \mathrm{mbgl}\end{array}$ & $\begin{array}{l}\text { Weak laminated grey mudstone } \\
\text { - from depths of } 4-9.7 \mathrm{mbgl}\end{array}$ \\
\hline \multicolumn{2}{|l|}{ Moisture content, w: \% } & $10-48(42)$ & $15 \cdot 3-19 \cdot 4(7)$ \\
\hline \multicolumn{2}{|l|}{ Liquid limit, $w_{\mathrm{L}}: \%$} & $52-102(30)$ & $54-63(4)$ \\
\hline \multicolumn{2}{|l|}{ Plastic limit, $w_{\mathrm{p}}: \%$} & $22-50(30)$ & $25-33(4)$ \\
\hline \multicolumn{2}{|l|}{ Plastic index, $I_{p}: \%$} & $28-55(30)$ & $23-28(4)$ \\
\hline \multirow{3}{*}{$\begin{array}{l}\text { UUTx - undrained shear strength } \\
\text { CUTx - effective stress }\end{array}$} & $\mathrm{C}_{\mathrm{u}}: \mathrm{kPa}$ & $95-314(18)$ & - \\
\hline & $c^{\prime}: \mathrm{kN} / \mathrm{m}^{2}$ & $4-28(6)$ & - \\
\hline & $\phi^{\prime}:$ degrees & $21 \cdot 5-37(6)$ & - \\
\hline \multirow{2}{*}{$\begin{array}{l}\text { Oedometer consolidation } \\
\qquad(100-400 \mathrm{kPa} \text { stress range) }\end{array}$} & $m_{\mathrm{v}}: \mathrm{m}^{2} / \mathrm{MN}$ & $0.081-1.069(8)$ & - \\
\hline & $c_{v}: m^{2} /$ year & $0 \cdot 109-2 \cdot 79(8)$ & - \\
\hline \multicolumn{2}{|l|}{ UCS: MPa } & - & $0 \cdot 43-63(18)$ \\
\hline \multicolumn{2}{|l|}{ CBR (lab) } & $2-12(16)$ & $11-20(4)$ \\
\hline
\end{tabular}

UUTx, unconsolidated undrained triaxial test; CUTx, consolidated undrained triaxial test; $m_{\mathrm{V}}$, coefficient of volume compression; $c_{\mathrm{V}}$, coefficient of consolidation; UCS, unconfined compressive strength; CBR, California bearing ratio.

Table 4. Summary of supplementary phase ground investigations material characterisation testing of Lower Lias clay and mudrock 
Geotechnical Research

Volume 2 Issue 3
The benefits of a granular interface over

pyritic subgrade

Czerewko and Cross

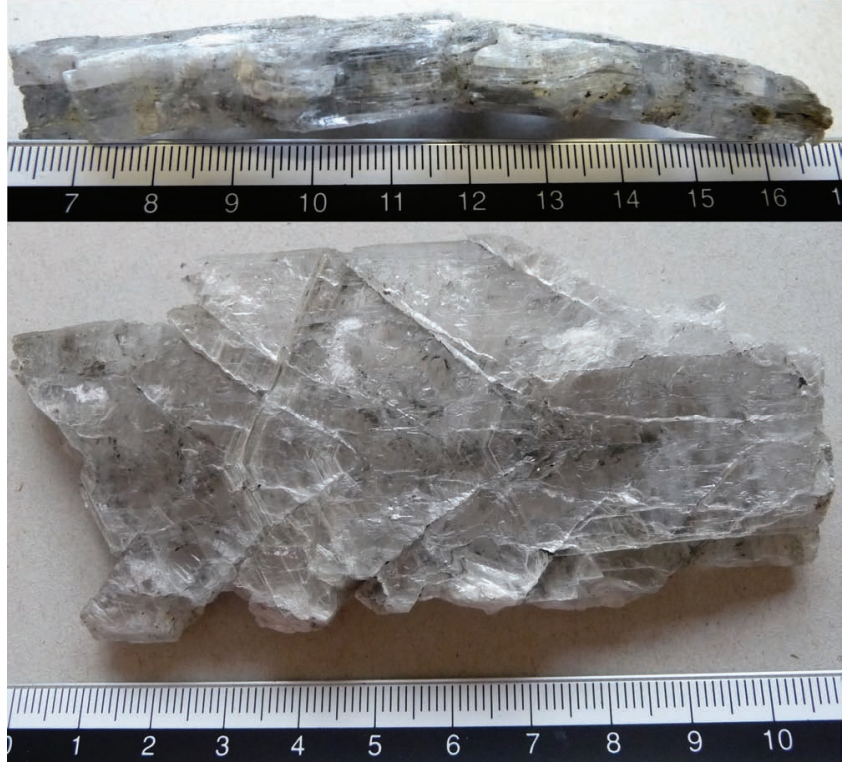

Figure 31. Selenite crystal development recovered from a dynamic slip plane

reaction with the products of pyrite oxidation in which gypsum is precipitated as selenite crystals.

A detailed examination of the physical and mineralogical characteristics of the mudrock was undertaken to understand the influences on the behaviour following exposure. The findings are summarised in detail by Czerewko et al. (2011). The strength of the mudrock was recorded as between 4.7 and $7 \mathrm{MPa}$, classing the material as weak mudstone. The slake durability was determined on a two-cycle test $\left(I_{\mathrm{d} 2}\right)$ and values of $I_{\mathrm{d} 2}$ of between $2 \%$ and $4 \%$ were recorded for the materials, indicating a material of extremely low durability. The static jar slake assessment recorded an index of

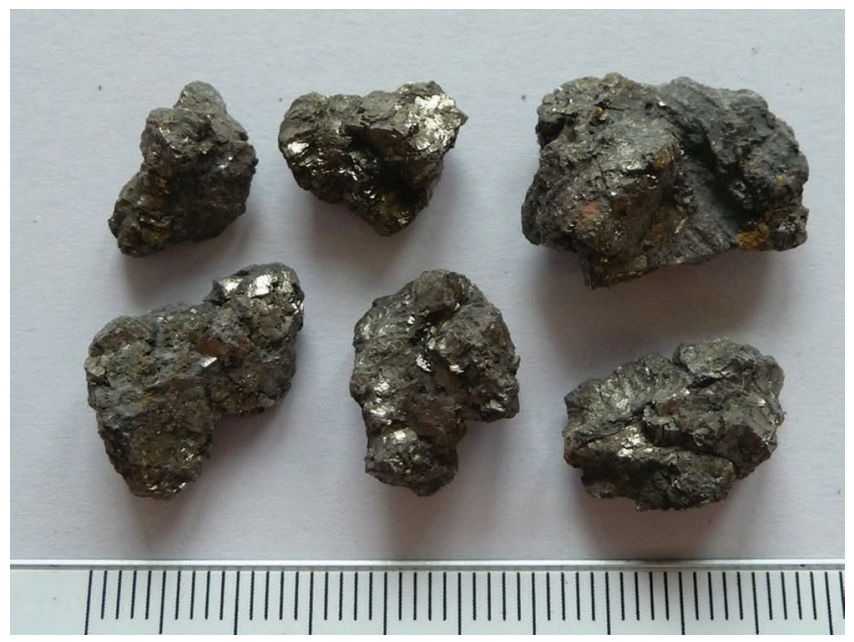

Figure 32. Clusters of interpenetrating cubic pyrite recovered from Lower Lias mudstone

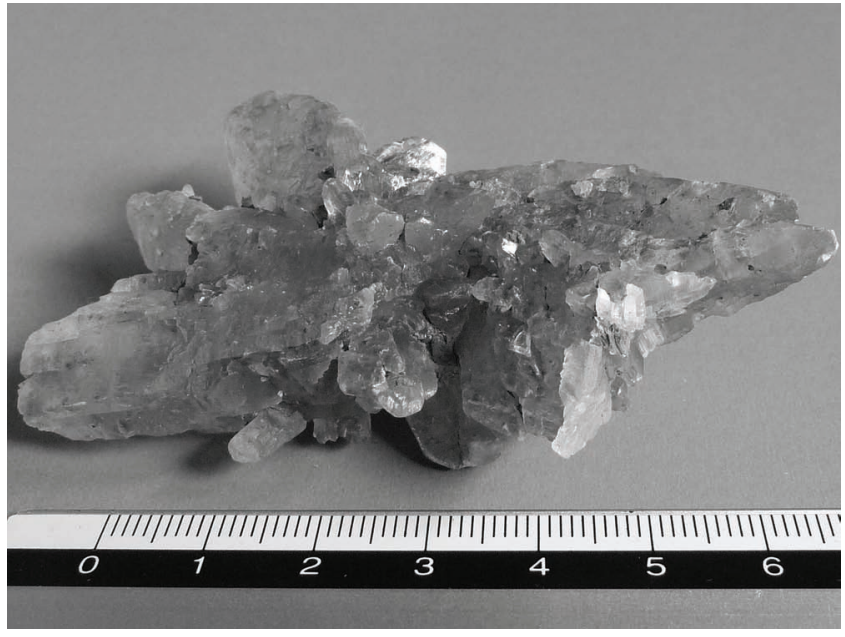

Figure 33. Selenite crystal cluster recovered from a mudstone bedding plane

$I_{\mathrm{j}^{\prime}}=8$. The samples underwent complete and rapid deterioration with significant loss of integrity, producing angular fine gravel sized debris with much silt and sand size material. The material was classed as a weak non-durable mudrock of extremely low durability. The assessment of the durability indicated a material susceptible to rapid physical degradation following exposure. The grading of the residual material comprised $2 \%$ fine gravel, $68 \%$ sand, $25 \%$ silt and $5 \%$ clay-size material. The fine fraction was non-plastic with a low volume change potential.

The mudrock fabric was examined using optical microscopy and scanning electron microscopy to determine the likely causes controlling the rapid breakdown and implications for pyrite oxidation. The observed structural fabric consists of an ordered arrangement of illite and kaolinite clay minerals as the claysize fraction with occasional silt-size clasts of detrital quartz. The fabric includes clay minerals with a disordered end-face

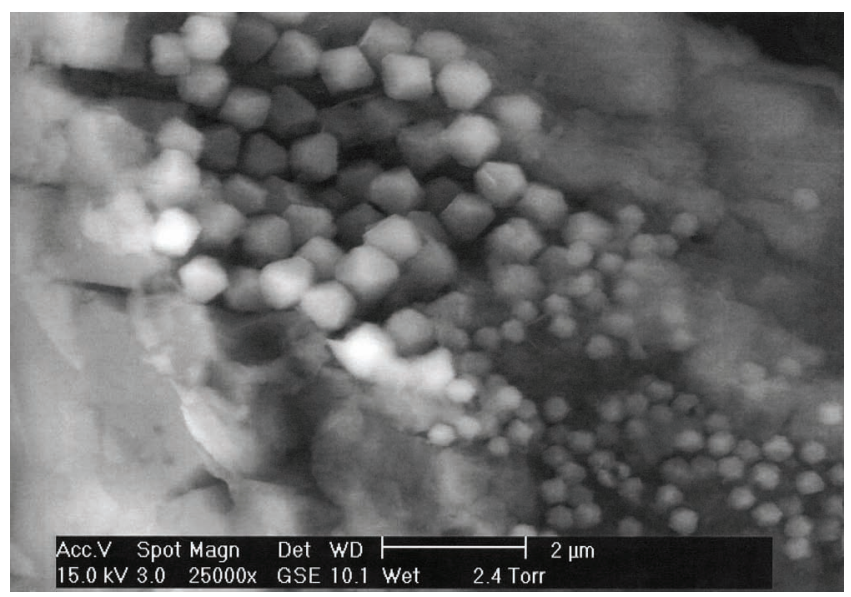

Figure 34. Disordered pyrite framboid 
Geotechnical Research

Volume 2 issue 3
The benefits of a granular interface over

pyritic subgrade

Czerewko and Cross 'turbostratic' arrangement and development of discrete silt to sand size particle clusters due to microfracture development typically attributed to stress relief with water interaction brought about by the effects of glaciation (Coulthard and Bell, 1993). Randomly oriented clay particles were observed between particle aggregates likely caused by fabric deterioration. This pronounced turbostratic structure seen in compaction clays and weak mudrocks produces anisotropic behaviour, particularly with regard to strength and deformation. The consequence of microfracturing also exposes pyrite framboids present to rapid ingress of air and water. This fabric may become rapidly destroyed by weathering and gradually disappears as the state of weathering increases.

Field weathering trials were carried out on the recovered mudrocks (Figure 35). The rapid degradation potential observed in the laboratory investigation was confirmed with progressive breakdown of fresh material over a 2-week period and development of a $<30 \mathrm{~mm}$ selenite crystal cover (Figure 36), and complete breakdown to a silt to gravel size product complete within $41 \mathrm{~d}$ (Figure 37). Laboratory performance assessment of shrink swell effects under wetting and drying conditions recorded approximately $12 \%$ of differential vertical movement which was believed to be an approximation of the possible movements that could occur in the engineered embankment and cut subgrade following construction (Czerewko et al., 2011). The laboratory and field studies concluded that rapid pyrite oxidation and mudrock degradation presented likelihood for ground heave with potential destructive effects to the highway following completion and degradation that would start following exposure.

Study of the material enabled an understanding of the behaviour at a site level and expediency in management of the construction process. The approach adopted allowed an understanding of the likely reaction and implications to construction at a site-specific level. Understanding of material characteristics enabled mitigation for the potentially long-term detrimental effects of pyrite oxidation. Fill materials were conditioned by loose stockpiling following

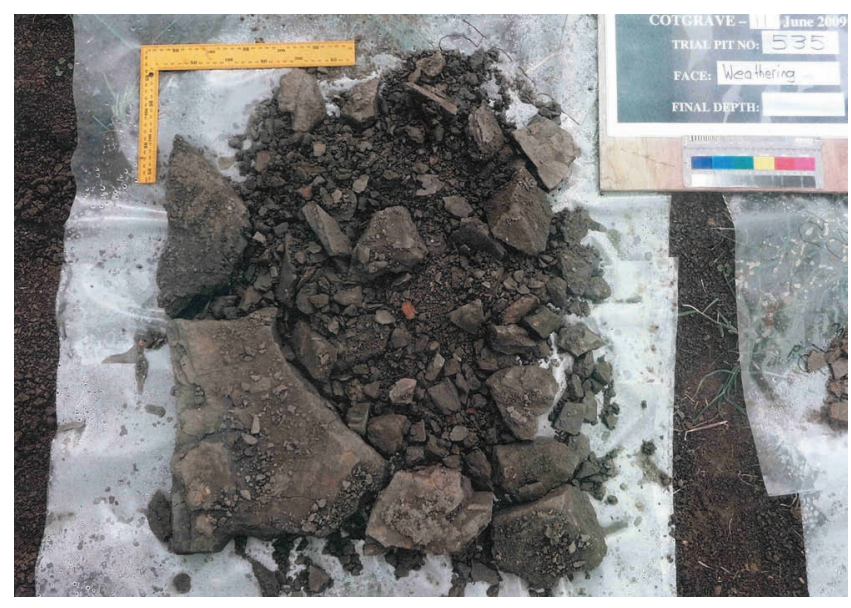

Figure 35. Mudrock material at start of weathering trial

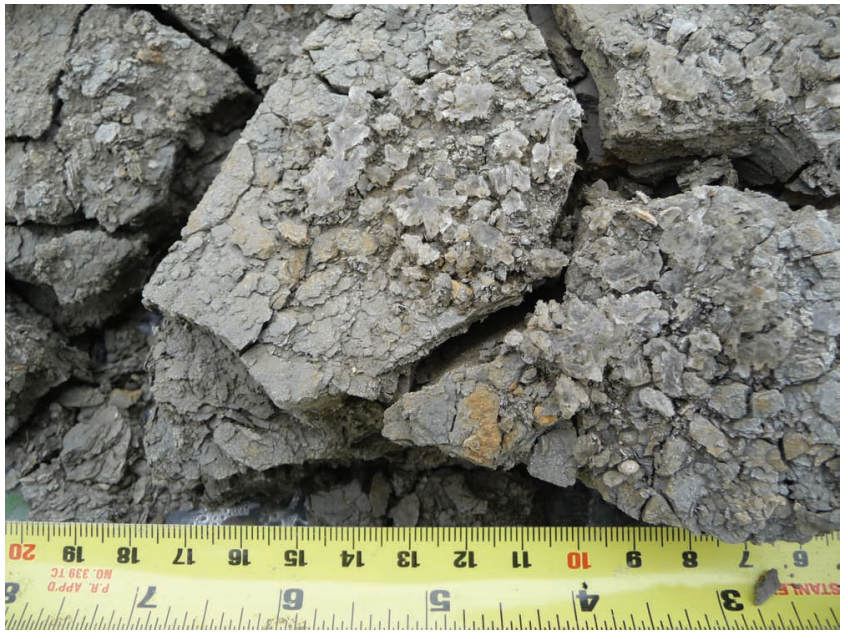

Figure 36. Development of selenite surface cover following 2 weeks of exposure

excavation, allowing rapid oxidation of pyrite and optimising crystallisation of selenite-gypsum. Exposure was controlled to allow sufficient time to enable chemical reaction to develop, followed by controlled earthwork compaction to limit further mineralogical deterioration of the fill and subgrade material. The construction sequence was managed to optimise material quality and the final cover system was engineered to inhibit water entry and limit pavement deterioration from subgrade softening.

During the 'rest' period, a $300 \mathrm{~mm}$ thick granular layer was placed over the subgrade for protection and as a construction interface for traffic movement across the site (Figure 17). The granular material comprised uniformly graded granite scalpings sourced from Mount Sorrel Quarry. The range of values for maximum rise of pore water were calculated taking the effective size $\left(D_{10}\right)$ of between 1 and
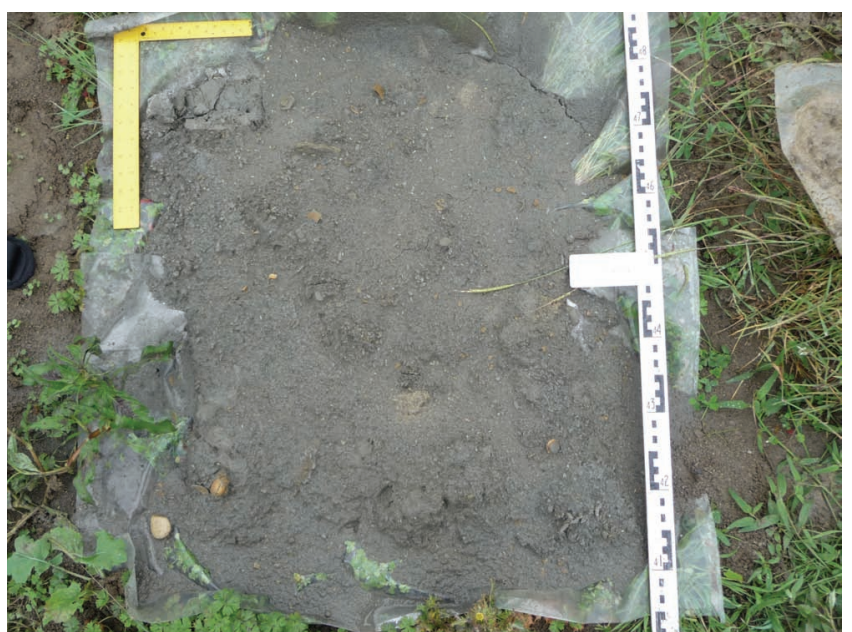

Figure 37. Completely degraded mudrock following 41 days exposure 
$2 \mathrm{~mm}$ from the material grading envelope, assuming a range of void ratios for well packed to poorly packed situations and assuming water constant for low to moderate contamination. The assessment showed that capillary rise was limited to less than $114 \mathrm{~mm}$ based on Hazen's method (in Barnes (2010) and Equation 3 in this paper). Therefore, a granular layer of $300 \mathrm{~mm}$ thickness was considered sufficient and included as a final granular interface to the overlying pavement and considered adequate as a flexible strain mitigation barrier and capillary break.

To date, there have been no signs of deterioration and the pavement remains in a satisfactory and fully serviceable condition.

\section{Discussion}

The degradation of pyritic mudrocks due to weathering oxidation can have serious consequences for road construction, particularly those involving earthworks. Potential deleterious implications include generation of chemically aggressive ground conditions, deterioration of pavements and slope instability due to heave, and reduced material strength. These conditions can develop rapidly, including during construction, and necessitate maintenance repair works to pavements and slopes, and the replacement of deteriorated construction material.

The principal types of deterioration that affect road construction involve destructive heave caused by selenite precipitation and chemical attack on concrete and stabilised ground treated using lime or cement. Essentially, the mechanisms involve chemical reactions brought about by the mobile sulfate anions $\left(\mathrm{SO}_{4}{ }^{2-}\right)$ that may occur in the soil, rock and groundwater. Sulfate anions may be derived by oxidation of pyrite through the natural process of weathering, which may be consequential of construction activities. As consequence of the production of acid by the release of protons in the weathering reactions, the chemical environment can become highly corrosive to buried steel and construction materials such as rock or soil fills and aggregates and concrete, producing deleterious reaction and heave.

Therefore, a suitable granular construction interface between pyritic subgrade and road construction offers a means of mitigation against such potentially deleterious consequences by providing an effective barrier to the upward migration of aggressive solutions and precipitation of new minerals. Thus, it is necessary to evaluate the type and distribution of both sulfides and sulfates in the ground and construction materials to establish the implications posed to construction and design appropriate remedial measures. Also, when assessing construction scenarios, factors such as disturbance to the ground brought about by excavation and replacement, soil mixing or excavation and placing as fill, and partial saturation above the water table must be considered.

Historical use of granular capping in road construction, particularly over pyritous clay of low bearing characteristics, has inadvertently mitigated and protected the road pavement against the deleterious effects of pyrite oxidation, particularly from differential heave and chemically aggressive conditions. The aim of a capping layer was to provide cost-effective reinforcement to an otherwise geotechnically unsound subgrade that would otherwise deform during trafficking.

The pavement design has generally not considered the development of deleterious ground conditions caused by pyrite oxidation as the subject is generally poorly understood and the potential consequences not clearly appreciated. Furthermore, the fact that granular capping abated the manifestation of otherwise potentially destructive conditions meant that the potential situations remained unnoticed. The granular capping not only provided the necessary support for the road construction over ground with poor bearing characteristics, but also provided a capillary barrier preventing upward migration of aggressive sulfate bearing groundwater.

\section{Conclusion}

The potential for differential movement may be anticipated from poorly to moderately indurate argillaceous deposits bearing fine disseminated pyrite, as demonstrated by the cases presented in this paper. These movements may have deleterious effects on the overlying pavement layers. Detailed review of ground conditions as part of the desk study in the early stage of the project should identify the presence of potentially pyritic ground. The presence of potentially pyritic lithologies should be confirmed by intrusive ground investigation and testing with detailed visual inspection of ground materials carried out by suitable experienced personnel familiar with recognition and assessment of potentially aggressive solutions. Examination should be carried out in situ from trial excavations where possible or by detailed inspection of continuously sampled ground material through the full construction profile. The testing of representative samples from each change in ground material and groundwater following visual examination will enable assessment of the risks posed to construction and enable appropriate design of mitigation. Where concerns arise as to the deleterious nature of ground material and the potential implications that this may pose to construction, it is recommended that mineralogical assessment is carried out, including microscopic assessment by a suitably experienced analyst.

Introduction of a granular construction interface layer between the subgrade and pavement layers would serve to mitigate differential movement. Current guidance for pavement construction requires the provision of suitable subgrade stiffness to provide suitable support for pavement foundation. Where the subgrade is of a lower natural stiffness, the guidance offers a number of traditional improvement options which are left to the discretion of the pavement designer. Previous guidance included provision of a capping layer in the design as standard and the thickness was based on assessment of long-term subgrade strength and groundwater conditions. Due to the changes presented in the design guidance and recent advances and use of HBM techniques, inclusion of an additional capping layer at the embankment-pavement interface tends to be overlooked by designers. 
The benefits of a granular interface over

pyritic subgrade

Czerewko and Cross

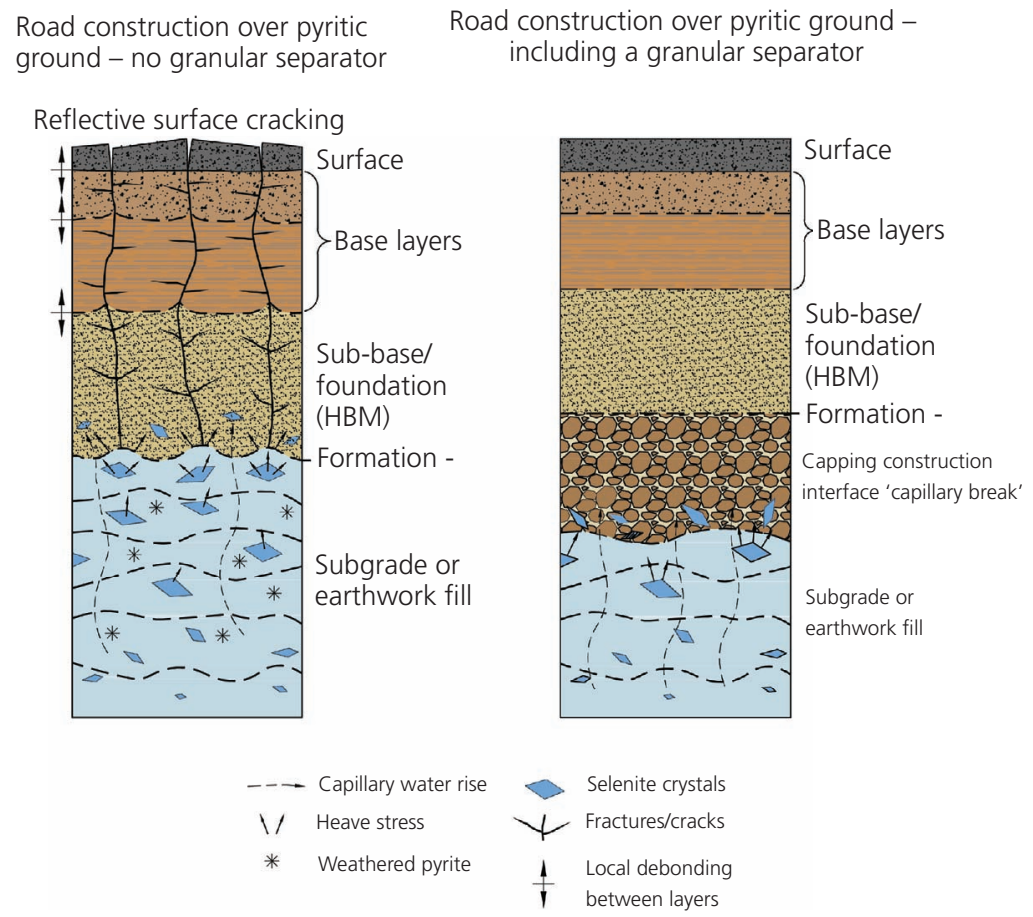

Figure 38. Schematic diagram demonstrating the benefits of a granular construction interface

A capping layer not only provides a strengthened formation surface during construction and for the pavement construction but also serves as a capillary separator against interaction between potentially aggressive subgrade material and the cementitious pavement layers. It also serves to reduce localisation of subgrade deformation resulting from softening of the clay at the subgrade interface or heave caused by crystallisation of selenite (Figure 38).

Although a capping or granular construction interface may not necessarily prevent the onset of weathering and degradation of pyrite-bearing argillaceous deposits following exposure and disturbance during construction, it will, however, serve to significantly mitigate these effects, in particular differential movement, heave and aggressivity from sulfate-bearing pore water solutions.

\section{Acknowledgement}

The authors gratefully acknowledge the support of the Highways Agency (now Highways England) for their consent for publication and encouragement in preparation of this paper. We are also grateful to the directors of Alfred McAlpine (now Carillion), Parkman, Balfour Beatty and Scott Wilson (now AECOM) for their encouragement in allowing the authors to prepare this paper.

\section{REFERENCES}

Barnes G (2010) Soil Mechanics: Principles and Practice, 3rd edn. Palgrave Macmillan, Basingstoke, UK.
Belgeri JJ and Siegel TC (1998) Design and performance of foundations in expansive shale. Proceedings of the Ohio River Valley Soils Seminar, Louisville, KY, USA.

Bell FG (1992) Engineering Properties of Soils and Rocks. Butterworth-Heinmann, London, UK.

Bowles JFW, Howie RA, Vaughan DJ and Zussman J (2011) Non-Silicates: Oxides, Hydroxides and Sulphides, Volume 5A, 2nd edn. The Geological Society, London, UK.

BRE (Building Research Establishment) (1991) Concrete in Sulphate-Bearing Soils and Water. BRE-IHS, Bracknell, UK, digest no. 363 .

BRE (2005) Concrete in Aggressive Ground. Part 1: Assessing the Aggressive Chemical Environment, BRE Special Digest 1, 3rd edn. BRE-IHS Bracknell, UK.

BSI (2007) BS EN 1997-2:2007: Eurocode 7: Geotechnical design. Part 2: Ground investigation and testing. BSI, London, UK.

BSI (2015) BS EN 5930:2015: Code of practice for ground investigations. BSI, London, UK.

Chaddock B and Roberts C (2006) Road Foundation Design for Major UK Highways. TRL, Crowthorne, UK, PPR127.

Coulthard JM and Bell FG (1993) The engineering geology of the Lower Lias Clay at Blockley, Gloucestershire, UK. Geotechnical and Geological Engineering 11(3): 185-201.

Cripps JC and Edwards RL (1997) Some geotechnical problems associated with pyrite bearing rocks. In Proceedings of International Conference on the Implications of Ground Chemistry and Microbiology for Construction (Hawkins AB (ed.)). Balkema, Rotterdam, the Netherlands, pp. 77-87. 
Cripps JC, Hawkins AB and Reid JM (1993) Engineering problems with pyritic mudrocks. Geoscientist 3(2): 16-19.

Czerewko MA, Cripps JC, Reid JM and Duffell CG (2002) The effects of sulfide oxidation and sulfate attack on concrete and buried steel structures in highways schemes. In Engineering Geology for Developing Countries - Proceedings of the 9th Congress of the International Association for Engineering Geology and the Environment (van Rooy JL and Jermy CA (eds)). South African Institute of Engineering and Environmental Geologists, Pretoria, South Africa, pp. 2465-2474.

Czerewko MA, Cross SA, Dumelow PG and Saadvandi A (2011) Assessment of pyritic Lower Lias mudrocks for earthworks. Proceedings of the Institution of Civil Engineers Geotechnical Engineering 164(2): 59-77.

HA (Highways Agency) (1994) HD 25/94: Pavement design and maintenance. Pavement design and construction. Foundations. In Design Manual for Roads and Bridges, vol. 7, section 2, part 2. Highways Agency, London, UK.

HA (2009a) Design Guidance for Road Pavement Foundations (Draft HD25). Highways Agency, London, UK, Interim Advice Note 73/06, Revision 1.

HA (2009b) Series 600 earthworks. In Manual of Contract Documents for Highway Works. Volume 1: Specification for Highways Works. Highways Agency, London, UK, pp. 1-31.

Hawkins AB (2014) Engineering implications of the oxidation of pyrite: an overview, with particular reference to Ireland. In The Implications of Pyrite Oxidation for Engineering Works (Hawkins AB (ed.)). Springer, Heidelberg, Germany, pp. 1-98.

Hawkins AB and Pinches GM (1987) Cause and significance of heave at Llandough Hospital, Cardiff - a case history of ground floor heave due to gypsum growth. Quarterly Journal of Engineering Geology 20(1): 41-57.

Hawkins AB and Pinches GM (1997) Understanding sulfate generated heave resulting from pyrite degradation. In Ground Chemistry Implications for Construction: Proceedings of the International Conference on the Implications of Ground Chemistry and Microbiology for Construction (Hawkins AB (ed.)). Balkema, Rotterdam, the Netherlands, pp. 51-75.

Higgins DD, Thomas B and Kinuthia J (2002) Pyrite oxidation, expansion of stabilised clay and the effect of ggbs. In
Performance of Bituminous and Hydraulic Materials in Pavements (Zoorob SE, Collop AC and Brown SF (eds)). Swets \& Zeitlinger, Lisse, the Netherlands, pp. 161-167. Holtz RD and Kovacs WD (1981) An Introduction to Geotechnical Engineering. Prentice-Hall, Englewood Cliffs, NJ, USA.

Lambe TW and Whitman RV (1979) Soil Mechanics, SI Version. Wiley, New York, NY, USA.

Lowson RT (1982) Aqueous oxidation of pyrite by molecular oxygen. Chemical Review 82(5): 461-497.

Pugh CE, Hossener LR and Dixon JB (1981) Pyrite and marcasite surface area as influenced by morphology and particle diameter. Soil Science Society of America Journal 45(5): 979-982.

Pye EK and Miller JA (1990) Chemical and biochemical weathering of pyritic mudrocks in a shale embankment. Quarterly Journal of Engineering Geology 23(4): 365-381.

Reid JM, Czerewko MA and Cripps JC (2005) Sulfate Specification for Structural Backfills. TRL Limited, Workingham, UK, report 447.

Sasaki M, Tsunekawa M, Ohtsuka T and Konno H (1998) The role of sulfur-oxidising bacteria Thiobacillus thio-oxidans in pyrite weathering. Colloids and Surfaces A: Physiochemical and Engineering Aspects 133(3): 269-278.

Snedker EA and Temporal J (1990) M40 Motorway Banbury IV Contract - lime stabilisation. Highways and Transportation 37(12): 7-8.

Taylor RK and Cripps JC (1984) Mineralogical controls on volume change. In Ground Movements and their Effects on Structures (Attewell PB and Taylor RK (eds)). Surrey University Press, Glasgow, UK, pp. 268-302.

Terzaghi K and Peck RB (1967) Soil Mechanics in Engineering Practice, 2nd edn. Wiley, New York, NY, USA.

Thaumasite Expert Group (1999) The Thaumasite Form of Sulfate Attack: Risks, Diagnosis, Remedial Works and Guidance on New Construction. Department of Environment, Transport and the Regions, London, UK.

West G (1996) Alkali-Aggregate Reaction in Concrete Roads and Bridges. Thomas Telford, London, UK.

Yamanaka T, Miyasaka H, Aso I, Tanigawa M and Shoji K (2002) Involvement of sulfur- and iron- transforming bacteria in heaving of house foundations. Microbiology Journal 19(5): 519-528.

\footnotetext{
WHAT DO YOU THINK?

To discuss this paper, please submit up to 500 words to the editor at journals@ice.org.uk. Your contribution will be forwarded to the author(s) for a reply and, if considered appropriate by the editorial panel, will be published as a discussion in a future issue of the journal.
} 